\title{
Nonsurgical Management of Esophageal Cancer
}

\author{
Malek M. Safa and Hassan K. Reda \\ Dayton Cancer Center, Dayton, Ohio and University of Kentucky, Lexington, Kentucky, \\ USA
}

\section{Introduction}

In the recent past, the incidence of esophageal adenocarcinomas has risen dramatically, whereas the incidence of squamous cell carcinomas has remained relatively steady in the United States (Holmes \& Vaughan, 2007). Esophageal adenocarcinoma arises from Barrett's esophagus with an estimated incidence rate of 0.4-0.7 per 100-patients/year. (Sharma et al., 2004; Thomas et al., 2007). Barrett's esophagus without dysplasia and those with low-grade dysplasia generally have low rates of disease progression, but some studies showed that over 8 years, $27 \%$ of patients with low-grade dysplasia developed high-grade dysplasia or early esophageal adenocarcinoma. In addition, high-grade dysplasia has a definite risk of disease progression with rates exceeding 10\% per year (Miros et al., 1991; Reid et al., 2000). The cornerstone of curative treatment for esophageal cancer has been surgery; however, its role has been challenged in very early stage due to morbidity of the procedure. Many studies have reported outcomes for patients undergoing surgical resection for esophageal cancer. However, the outcome of such studies does not inform clinical decision making for the majority of patients who present to surgeons with esophageal cancer. Esophagectomy for high-grade dysplasia or early esophageal carcinoma has mortality rates ranging from 2.5 to $20.3 \%$ and $30-50 \%$ of patients may develop serious postoperative complications (Spechler, 2005). For a variety of reasons, the majority of patients with esophageal cancer are actually not suitable for esophagectomy. More than 50\% have locally advanced, unresectable or metastatic tumors at diagnosis. Other reasons which preclude esophagectomy include old age, comorbidity, or refusal by the patient. Emerging data suggest that endoscopic therapies are viable therapeutic options with significantly lower morbidities. Currently, in many institutions, for a subset of patients with clinically localized early stage esophageal cancer (T0 or T1 lesions), local endoscopic therapy (excisional biopsy, endoscopic resection, photodynamic, local destruction, thermal laser, polypectomy, electrocautery, cryoablation, or radiofrequency ablation) seems to be an acceptable alternative and produces similar results to surgery.

For more advanced stages of esophageal cancers, the mainstay of nonsurgical treatment is chemotherapy (CT) or radiotherapy (RT), either alone or in combination chemoradiotherapy (CRT). A number of factors have been shown to predict survival in advanced esophageal cancer. These include stage, performance status, weight loss, and presence or absence of metastasis. The stage of the cancer, and in particular the presence of metastatic disease, is 
the single strongest predictor. The influence of other factors, such as histological type, has been less well established. However, there is data suggesting that standard CRT might be equivalent to surgery alone in terms of survival for patients with squamous cell carcinoma of the esophagus.

In this chapter, we sought to determine the outcome of patients who underwent treatment of esophageal cancer with the various local endoscopic therapies, conventional CT or RT or concurrent CRT, but not surgical resection, as published in the literature. In addition, we reviewed the specific outcomes of patients with and without metastatic disease, and with different histological subtypes.

\section{Endoscopic mucosal resection}

Endoscopic mucosal resection (EMR) serves both diagnostic and therapeutic roles in the management of Barrett's esophagus and early esophageal cancer. It involves local snare excision of the target lesion. EMR resects a lesion in entirety for histopathological assessment, and if the resection margins are clear, it is curative. It has also been used to completely resect the entire at-risk Barrett's epithelium in order to reduce the risk of recurrence.

Ell et al. (Ell et al., 2007) evaluated the efficacy and safety of localized endoscopic mucosal resection in a total of 100 patients with low-risk early esophageal adenocarcinomas (lesion diameter up to $20 \mathrm{~mm}$; mucosal lesion without invasion into lymph vessels and veins; and histopatholological grade G1 and G2). Complete local remission was achieved in 99 of the 100 patients after 1.9 months and a maximum of three resections. During a median followup period of 36.7 months, recurrent or metachronous carcinomas were found in $11 \%$ of the patients, but successful repeat treatment with endoscopic resection was possible in all cases. There were no major complications.

To address the problem of disease recurrence, the concept of complete circumferential EMR to remove all underlying Barrett's mucosa upon detection of high-grade dysplasia or early esophageal carcinoma was introduced. In an early study (Seewald et al., 2003), 12 patients with high-grade dysplasia or early esophageal carcinoma underwent circumferential EMR using simple snare resection. During a median follow-up of 9 months, no recurrence of Barrett's esophagus or malignancy was observed. Giovannini et al. (Giovannini et al., 2004) subsequently reported their experience in circumferential EMR in 21 patients with Barrett's esophagus who had either high-grade dysplasia or early esophageal carcinoma. Complete circumferential EMR was achieved in two sessions. Resection was complete in $86 \%$ of the patients and Barrett's esophagus was completely replaced by squamous cell epithelium in $75 \%$. Later studies reported similar results with rare complication rates including stricture formation, bleeding and perforations. (Peters et al., 2006; Larghi et al., 2007; Lopes et al., 2007).

In summary, although EMR is feasible, safe and effective for the treatment Barrett's esophagus with high-grade dysplasia and early esophageal carcinoma, more long-term data for a larger number of treated patients are still required in order to establish EMR as a standard alternative treatment to surgery. 


\section{Photodynamic therapy}

Photodynamic therapy (PDT) is one of the most widely studied ablative therapies used in the treatment of Barrett's esophagus. PDT is one of the most acceptable ablative therapies for high-grade dysplasia and early invasive adenocarcinoma with some of the longest follow-up data (Prasad et al., 2007).

\subsection{Technique}

PDT is a photochemical process that requires multiple steps to achieve tissue destruction. First, a photosensitizer drug is required. The only photosensitizer approved in the United States by the Food and Drug Administration for use in Barrett's high-grade dysplasia is porfimer sodium (Ps) (photofrin). Usually, porfimer sodium is administered intravenously over 3 to 5 minutes at a dose of $2 \mathrm{mg} / \mathrm{kg}$ body weight. After systemic injection, the photosensitizer is absorbed by most tissues and retained at higher concentrations in neoplastic tissues (Nishioka, 1998). The second step in the process is the application of light of proper power and wavelength to the target tissue. A variety of tunable dye lasers have been approved to activate photosensitizers. These laser units can generate the desired light and about 2 to $2.5 \mathrm{~W}$ of energy output. Visible red light at approximately $630 \mathrm{~nm}$ is typically used to activate the photosensitizer. The activated drug interacts with molecular oxygen leading to the generation of singlet oxygen. Subsequent radical reactions can form superoxide and hydroxyl radicals leading to cell membrane damage and apoptosis. It is important to note that laser treatment induces a photochemical, and not a thermal effect. For endoscopic applications, illumination with laser light occurs 40 to 50 hours after injection with porfimer sodium (Overholt et al., 2005). The light is transmitted by optical fiber advanced through the accessory channel of an endoscope. The fibers come in different lengths to better match the length of the lesion being targeted. For treatment of BE with high-grade dysplasia, the light dose recommended is 130 to $200 \mathrm{j} / \mathrm{cm}$ fiber. A second endoscopy is advised 96 to 120 hours after porfimer sodium injection to assess mucosal damage and degree of necrosis. If needed, a second light application can be administered to skipped or poorly treated areas (Overholt et al., 2005). The depth of injury of porfimer sodium at wavelength of $630 \mathrm{~nm}$ is approximately 5 to $6 \mathrm{~mm}$, depending on tissue blood flow and oxygen levels (Gross \& Wolfsen, 2010).

There are other drugs, used mostly in Europe, for PDT applications, including 5aminolevulinic acid (5-ALA) and m-tetrahydroxyphenyl chlorine (mTHPC). ALA is present in all cells and is the first intermediate of the biochemical pathway resulting in heme synthesis. ALA differs from other drugs in that it is not a preformed photosensitizer but rather a precursor of the endogenously formed photosensitizer protoporphyin IX (Dunn \& Lovat, 2008). Advantages of ALA over Ps are the ability to administer it orally; the shorter duration of skin photosensitivity (24-48 hours); and the selective destruction of the mucosa that does not induce development of strictures (Pech et al., 2005). In 2007, 5-ALA was granted drug approval by the Food and Drug Administration for the treatment of patients with Barrett's high-grade dysplasia.

\subsection{Clinical applications}

Porfimer sodium first received approval in the United States in 1995 for palliation of patients with advanced esophageal carcinoma. This led to a number of studies using Ps-PDT 
for treatment of dysplastic Barrett's mucosa. Overholt and colleagues reported 100 patients treated with PDT including 73 patients with high-grade dysplasia, 14 patients with lowgrade dysplasia, and 13 patients with T1 or T2 adenocarcinoma (Overholt et al., 1999). Patients were followed for a mean of 19 months while on omeprazole. Small residual areas of Barrett's mucosa were treated with Nd: YAG laser. Seventy-three patients received one PDT treatment, twenty-two received two treatments, and five patients received three treatments. The results showed that $92 \%$ with low-grade dysplasia, $88 \%$ with high-grade dysplasia, and $77 \%$ of cancers were eradicated by PDT and focal thermal ablation. In $43 \%$ of patients, there was complete elimination of all Barrett's mucosa. The most common complication reported was the development of strictures in $34 \%$ of patients.

In another study (Wolfsen et al., 2002), 48 patients (14 patients with T1 cancers and 34 patients with high-grade dysplasia) were treated with only one course of PDT, and any residual Barrett's tissue was subsequently treated with argon plasma coagulation (APC). Complete and successful ablation of all high-grade dysplasia and cancer was achieved in 47 of 48 patients. One patient with persistent cancer underwent curative esophagectomy. Most frequent complications included stricture formation in 11 patients $(23 \%)$; photosensitivity in 7 patients (15\%); and esophageal perforation in 1 patient $(2 \%)$.

Other studies confirmed the benefits of PDT therapy (Overholt et al., 2003; Wolfsen et al., 2004) which led to the first randomized controlled trial in patients with high-grade dysplasia (Overholt et al., 2005). The study included 30 sites and used a centralized pathology laboratory. A total of 208 patients were entered into the study and randomized in a 2:1 ratio to omeprazole plus PDT (138 patients) versus omeprazole alone (70 patients). Patients could receive up to three courses of PDT. Follow-up consisted of endoscopy and four-quadrant biopsies every $2 \mathrm{~cm}$ performed every 3 months until four consecutive quarterly biopsies were negative for high-grade dysplasia, then every 6 months thereafter. The mean follow-up was 24 months. Complete ablation of HGD was achieved in $77 \%$ of patients in the omeprazole plus PDT group compared to with 39\% in the omeprazole alone group ( $\mathrm{p}<0.0001)$. Complete eradication of all Barrett's esophagus and dysplasia was seen in $52 \%$ of patients in the PDT group compared with $7 \%$ in the omeprazole group $(\mathrm{p}<$ 0.0001). There was also a significant difference in progression to cancer, with $13 \%$ of patients in the PDT group developing cancer compared with $28 \%$ in the omeprazole group. The most common PDT-related events were photosensitivity reactions $(69 \%)$, esophageal strictures $(36 \%)$, vomiting $(32 \%)$, non-cardiac chest pain $(20 \%)$, pyrexia $(20 \%)$, and dysphagia $(19 \%)$. The results of this study led the Food and Drug Administration to approve the use of PDT with porfimer sodium for the treatment of Barrett's with high-grade dysplasia. A 5-year follow-up of the original study demonstrated the persistent superiority of PDT in eliminating high-grade dysplasia long-term $(77 \%$ in the treatment group vs. $39 \%$ in the omeprazole group). However, only 61 patients of the 102 patients eligible were enrolled in the long-term follow-up phase. Progression to cancer remained significantly lower in the PDT group $(15 \%)$ compared with $29 \%$ in the omeprazole group $(p=.027)$. There was also a significantly longer time to progression to cancer favoring PDT $(\mathrm{p}=.004)$.

Based on these encouraging results, multiple studies evaluated PDT for the treatment of patients with early esophageal cancer who are not candidates for surgical resection. Moghissi and colleagues reported their long-term experience in treating patients with early stage esophageal cancer with PDT (Moghissi et al., 2009). Among 144 patients treated with 
PDT, 40 had T1 tumors (35 adenocarcinomas and 5 squamous cell carcinomas). At median follow-up of 76.1 months (range 36-150 months), 3 and 5 years or more survival were $72.5 \%$ and $53.8 \%$ respectively. In another study, 24 patients with early esophageal cancer were treated with PDT (Maunoury et al., 2005). Seventy-five percent of the patients were treated successfully. At a median follow-up of 21 months, $54 \%$ of patients were still alive without recurrence. The authors concluded that PDT should be considered as the treatment of choice in patients with early esophageal cancer who are ineligible for surgical resection.

PDT has also been combined with endoscopic mucosal resection (EMR) for treatment of dysplasia and intramucosal cancers in Barrett's esophagus. In one study (Buttar et al., 2001), 17 patients with either T0 or T1 esophageal adenocarcinoma were treated by EMR followed by PDT therapy. At a median follow-up of 13 months, 16 patients $(94 \%)$ remained in clinical and histologic remission. Three patients with positive mucosal resection margins remained cancer-free after PDT. In a retrospective study (Prasad et al., 2009) from Mayo Clinic, patients with T1 esophageal adenocarcinoma in Barrett's esophagus were treated either endoscopically (either EMR or EMR followed by PDT therapy) or with esophagectomy. There were 132 patients in the endoscopy-treated group (75 with EMR alone and 57 with EMR plus PDT) and 46 in the surgically treated group. Patients treated by endoscopy were older and had more medical comorbidities than those treated surgically. Remission was successful in $91 \%$ of patients treated with EMR plus PDT and in $96 \%$ of patients treated with EMR alone. Five-year overall survival was comparable in the endoscopy treated group $(83 \%)$ and the surgical group (95\%). In the endoscopy group, 16 patients had recurrent carcinomas detected during follow-up, and all except one were managed by EMR. The presence of residual dysplastic Barrett's esophagus was a significant factor predicting recurrent carcinoma on univariate analysis.

\subsection{Response predictors}

There have been a few long-term studies evaluating predictors of response to PDT and risk factors for recurrence of dysplasia. In one retrospective study of 116 patients with Barrett's high-grade dysplasia, and intramucosal adenocarcinoma treated with PDT, pretreatment length of BE was inversely correlated with successful ablation of all Barrett's epithelium. The presence of intramucosal adenocarcinoma or T1 cancer was not associated with higher likelihood of treatment failure (Yachimski et al., 2009). In another study (Badreddine et al., 2010) evaluating 261 patients treated with PDT with and without EMR, significant predictors of recurrence of dysplasia or neoplasia on multivariate analysis were older age, presence of residual nondysplastic Barrett's esophagus, and history of smoking. Biomarkers have been examined as potential predictors of response to PDT. Using fluroscence in situ hybridization, one group found that p16 allelic loss predicted decreased response to PDT (Prasad et al., 2008).

\subsection{Complications}

The most common side effects reported within hours of PDT include chest pain, nausea, dysphagia and odynophagia. These are commonly treated with analgesics, both topical and systemic. These symptoms usually resolve within 1 to 2 weeks after therapy. Photosensitivity has been reported in as many as $69 \%$ of patients treated with PDT. Photosensitivity may last 
anywhere from 4 to 8 weeks. Patients are also sensitive to strong indoor lighting. Symptoms may range from mild erythema to blistering and even bullae formation. However, by far, the most significant long term toxicity of PDT is stricture formation, reported in up to one third of patients (Overholt et al., 1999, 2005). The underlying mechanism of stricture formation after PDT might be due to deep tissue injury which leads to an aggressive fibrotic response that produces structuring. Risk factors for development of strictures include history of previous esophageal stricture, performance of EMR before PDT, and more than one PDT application in one treatment session (Prasad et al., 2007). Another study identified the following independent predictors of stricture development: longer segment Barrett's, multiple PDT treatments, and evidence of intramucosal carcinoma before PDT (Yachimski et al., 2008). Other less common complications include fever, vomiting, cardiac arrhythmias and development of pleural effusions.

\subsection{PDT with 5-ALA}

In the only double-blind, randomized placebo-controlled study reported of ALA-PDT, 36 patients with Barrett's esophagus and low-grade dysplasia were randomized to receive oral ALA or placebo (Ackroyd et al., 2000). All patients were treated with green light and maintained on omeprazole. Responses were seen in $89 \%$ of patients in the ALA-PDT group, with a median decrease in area in the treated region of 30\% (range, $0-60 \%$ ). In the placebo group, a median area decrease of $0 \%$ was seen (range, $0-10 \%$ ). Furthermore, there was complete eradication of low-grade dysplasia in all 18 patients in the ALA-PDT group, compared with only 6 of $18(33 \%)$ in the placebo group $(\mathrm{p}<.001)$.

The first long-term study of ALA-PDT in Barrett's esophagus with high-grade dysplasia and T1 adenocarcinoma was reported by Pech and colleagues (Pech et al., 2005). A total of 66 patients (35 with high-grade dysplasia and 31 with intramucosal cancer were treated with ALA-PDT. Median follow-up was 37 months. Complete remission was achieved in 34 (7\%) of 35 patients with high-grade dysplasia. Six patients developed a recurrence or a metachronous lesion, but five of these underwent successful repeat treatment. In the intramucosal carcinoma group, complete remission was achieved in all patients but nine patients had recurrence of metachronous carcinoma (29\%). Seven patients were successfully treated with ALA-PDT, one went for surgery and one was not a surgical candidate and received palliative treatment 2 years later. The 5-year survival was $97 \%$ in the high-grade dysplasia group and $80 \%$ in the carcinoma group (Pech et al., 2005).

However, other studies of ALA-PDT have shown somewhat disappointing results (Peters et al., 2005) and high-recurrence rate in patients with early cancer (Pech et al., 2005). This variability in results could be caused by multiple factors including 5-ALA dose; light dose; and type of light used (green vs. red).

In general, 5-ALA has an acceptable safety profile. The most common side effects reported include nausea, vomiting, hoptension and transient photosensitivity and rise in liver enzymes.

\subsection{Summary}

PDT has been a critically important tool for the advancement of endoscopic therapy for esophageal dysplasia and superficial carcinoma. PDT is an effective method to eradicate 
high-grade dysplasia and to significantly reduce the risk of progression to cancer in Barrett's esophagus. There are advantages of PDT over other treatment modalities including ease of use, the need for fewer endoscopic sessions; and when compared with surgery, reduced morbidity, mortality and even cost. However, in the era of newer endoscopic ablative methods, PDT faces a number of challenges, such as the well-described complications of prolonged photosensitivity, high rate of stricture formation, and the severe pain and discomfort caused by the photochemical reaction. Therefore, to remain a viable clinical option, PDT candidates should be carefully selected to obtain more uniform results, minimize side effects, and maximize treatment outcomes while reducing complications.

\section{Argon plasma coagulation}

Argon plasma coagulation (APC) is a noncontact thermal technique using ionized argon gas to deliver a monopolar high-frequency current, which effectively coagulates tissue. APC is applied to tissue until a white coagulum appears, and then the catheter and endoscope are manipulated in a vertical or circumferential linear pattern to coagulate additional tissue. The depth of tissue destruction is thought to be limited due to increased resistance and diminished current flow through coagulated tissue, although perforation has occurred with this technique.

Multiple prospective studies have examined the efficacy and safety of APC for Barrett's ablation. The majority of these studies enrolled patients with Barrett's esophagus without dysplasia, while a few included patients with both low-grade dysplasia and high-grade dysplasia (Attwood et al., 2003; Pereira-Lima, et al., 2000; Ragunath et al., 2005). APC was effective in completely eradicating intestinal metaplasia in $58 \%-100 \%$ of cases, depending on the series. Recurrence was seen in most studies and was reported in 3\%-66\% of patients followed. In one trial (Attwood et al., 2003), APC was used in patients with Barrett's esophagus and high-grade dysplasia with a response in 25 of 29 patients (86\%).

Serious complications and less severe side effects have been reported. Perforation, often requiring thoracotomy, was reported in $0 \%-3.6 \%$ of cases. Other serious adverse events include stricture formation (0\%-15.4\%) and major bleeding (0\%-3.9\%). Chest pain was reported frequently $(1.8 \%-54.5 \%)$, and one study reported dysphagia and odynophagia in over half the patients (Pereira-Lima et al., 2000).

Another method of ablation is Multipolar electrocoagulation (MPEC) which requires contact with the mucosa across the electrode contacts at the tip of the catheter. MPEC was evaluated in a prospective multicenter trial of patients with non-dysplastic Barrett's esophagus (Sampliner et al., 2001). Among the 72 patients enrolled, $78 \%$ of patients achieved a complete response rate for elimination of Barrett's esophagus. A randomized controlled trial compared APC with MPEC in 52 patients (Dulai et al., 2005). Residual Barrett's esophagus was found in both groups and response rates were similar (MPEC 81\% vs. APC 65\%, $\mathrm{P}=0.21)$.

In summary, most experts do not recommend routine ablation of nondysplastic Barrett's esophagus by APC or other modality at this time. The relatively high incidence of complications, low rate of progression to cancer, and lack of long-term data on the effectiveness of eradication in preventing cancer progression confine ablation of 
nondysplastic Barrett's esophagus to the research setting in most cases. Ablation of highgrade dysplasia or intramucosal carcinoma in Barrett's esophagus has been studied, but the limited data available in this patient group make it difficult to recommend APC for routine care.

\section{Cryotherapy}

Cryotherapy is the application of extremely cold temperatures to tissues for medical treatment. Several agents were tried until liquid nitrogen was introduced in 1950 by Allington using a cotton swab applicator for the treatment of skin lesions (Allington, 1950). Cryotherapy destroys biological tissue through a variety of methods. These can be divided into immediate and delayed effects. Rapid freezing causes failure of cellular metabolism due to stress on lipids and proteins. Continued freezing produces extracellular ice, creating a hyperosmotic extracellular environment and drawing fluid from cells. This leads to further damage of cell membrane resulting in cell death.

Cryospray ablation (CSA) uses low-pressure liquid nitrogen spray delivered through a 7-Fr catheter passed through the working channel of a standard upper endoscope. The first report of the CSA device as used in humans related 11 patients with Barrett's esophagus (Johnston et al., 2005). Low-grade dysplasia was present in 5 patients and high-grade dysplasia in 1 patient. In this pilot study, 9 of the 11 patients had complete histologic reversal of Barrett's esophagus, with no dysplasia found at 6-months follow-up. No significant complications occurred and the treatment was well tolerated. In a subsequent pilot study (Dumot et al., 2007) of CSA and endoscopic mucosal resection, 30 high-risk patients were treated with serial cryotherapy sessions every 6 weeks until there was resolution of high-grade dysplasia and intramucosal carcinoma. The overall complete response (CR) of eliminating cancer or downgrading high-grade dysplasia was $73 \%$ for high-grade dysplasia and $80 \%$ for intramucosal carcinoma.

A retrospective study reported the efficacy of endoscopic spray cryotherapy for esophageal cancer (Greenwald et al., 2010). In this study, there were 79 patients with esophageal carcinoma (60 with T1, 16 with T2, and 3 with T3-T4). Previous treatment including endoscopic resection, photodynamic therapy, esophagectomy, chemotherapy, and radiation therapy failed in 53 subjects (67\%). Mean length of follow-up after treatment was 10.6 months overall. Complete response was seen in 31 of $49(61.2 \%)$ patients who finished treatment.

A prospective study evaluated the safety and tolerability of cryotherapy in 77 patients at four academic medical centers in the United States (Greenwald et al., 2008). This group included patients with Barrett's esophagus with high-grade dysplasia, low-grade dysplasia, intramucosal carcinoma and invasive carcinoma. The most common side effects in 323 procedures included chest pain (17.6\%), dysphagia (13.3\%), odynophagia (12.1\%), and sore throat $(9.6 \%)$. Gastric perforation occurred in one patient with Marfan's syndrome. Three patients developed esophageal strictures.

In conclusion, there is a need for improvement to the current CSA technology. Currently, treatment can be limited by patient tolerance and variables outside of the physician's 
control. These technological advancements will provide longer spray times applied to thicker lesions, and provide therapeutic effect into deeper tissue levels.

The immune reaction induced by CSA may be the most exciting feature of this therapy. Other heat-based ablation methods such as APC and PDT tend to cause an eschar with denaturated proteins compared to apoptosis induced by CSA, which may lead to immune system stimulation as demonstrated by the inflammatory infiltrate visible on full-thickness histologic specimens.

\section{Laser and thermal therapy}

Lasers have been studied in Barrett's esophagus and esophageal cancer, including potassium-titanyl-phosphate (KTP), neodymium: yttrium-aluminum-garnet (Nd:YAG), and argon lasers.

KTP laser treatment resulted in complete response in 10 patients with Barrett's esophagus with low-grade dysplasia (4 patients), high-grade dysplasia (4 patients), and intramucosal carcinoma (2 patients) (Gossner et al., 1999). The KTP laser emits a light with $532 \mathrm{~nm}$ wavelength that is preferentially absorbed by hemoglobin, making it useful for vascular lesions.

Nd: YAG, emitting light at $1064 \mathrm{~nm}$, provides a deeper penetration as it vaporizes tissue. Nd: YAG laser was used in conjunction with MPEC in six patients with intramucosal carcinoma who were deemed to be high-risk candidates for surgery (Sharma et al., 1999). All patients had a complete initial response and one developed a recurrence at 36 months. In a large prospective randomized trial of 236 patients with advanced esophageal cancer, PDT and Nd: YAG were overall similarly effective in palliation of dysphagia, although PDT has an advantage in upper and mid-thoracic tumors and for long tumors (Lightdale et al., 1995). PDT was associated with fewer side effects (3\% vs. 19\%) excluding photosensitivity and perforations ( $1 \%$ vs. $7 \%)$.

Thermal coagulation with a heat probe was used to treat 13 patients with nondysplastic Barrett's esophagus 2-6 cm long (Michopoulos et al., 1999). Three of the 13 had subsquamous intestinal metaplasia and two had a relapse on follow-up thought to be due to noncompliance with acid suppression medications. One patient developed low-grade dysplasia during surveillance.

\section{Radiofrequency ablation}

Stepwise circumferential and focal radiofrequency ablation (RFA) using the HALO system is a relatively new endoscopic treatment modality for Barrett's esophagus. Recent studies suggest that this ablation technique is highly effective in removing Barrett's mucosa and associated dysplasia without the aforementioned drawbacks of other ablation techniques (Sharma et al., 2006, 2007, 2008; Fleischer et al., 2008; Shaheen et al., 2008; Gondrie et al., 2008).

\subsection{Technique and procedure}

The HALO system comprises two distinct ablation systems: the HALO ${ }^{360}$ system for primary circumferential RFA and the $\mathrm{HALO}^{90}$ system for secondary focal RFA or primarily 
as treatment for short-segment Barrett's esophagus. Prior to circumferential RFA, a sizing catheter with a 4-cm long noncompliant balloon at its distal end is used to measure the inner esophageal diameter. Upon activation via a foot switch, the sizing balloon is inflated by the $\mathrm{HALO}^{360}$ energy generator, and the mean esophageal inner diameter is automatically calculated for the entire length of the 4-cm long ablation. Focal RFA of Barrett's esophagus may be conducted with the HALO ${ }^{90}$ system, which consists of an endoscope-mounted ablation catheter and an energy generator similar to the $\mathrm{HALO}^{360}$ generator, but without the pressure: volume system.

Stepwise circumferential and focal ablation of a Barrett's esophagus generally starts with a circumferential ablation procedure using the HALO ${ }^{360}$ system, which comprises the following steps: recording esophageal landmarks, sizing inner esophageal diameter, selecting the appropriate $\mathrm{HALO}^{360}$ ablation catheter, first circumferential ablation pass, cleaning procedure between ablation cycles, and second ablation pass. A minimum of 8 weeks after the first circumferential ablation treatment, patients are rescheduled to undergo a second ablation. Patients with residual circumferential Barrett's esophagus greater than $2 \mathrm{~cm}$ in size and/or multiple isles or tongues are treated with a second circumferential ablation. Patients with an irregular Z-line, small tongues, circumferential extent below $2 \mathrm{~cm}$, or diffuse isles are treated with focal ablation using the HALO 90 system.

Post-treatment care includes proper acid suppressant therapy to minimize patient discomfort and to allow the esophagus to heal optimally and regenerate with squamous epithelium. Patients should be prescribed high-dose proton-pump inhibitors as maintenance medication. Additional H2-receptor antagonists and sucralfate can be prescribed. After RFA, patients are advised to adhere to a liquid diet for 24 hours, then they may gradually expand to a soft and then normal diet. Patients may experience symptoms of chest discomfort, sore throat, difficulty or pain with swallowing, and/or nausea. Proposed analgesic measures are viscous lidocaine, liquid acetaminophen with or without codeine, and antiemetic medication.

Two to three months after the last treatment, the absence of residual Barrett's epithelium is verified by endoscopic inspection. A strict biopsy protocol should be applied with fourquadrant biopsies immediately distal $(<5 \mathrm{~mm})$ to the neosquamocolumnar junction and every 1-2 cm of the neosquamous epithelium. Since no long-term follow-up data after RFA are available thus far, it is recommended to schedule patients for follow-up endoscopy 2 and 6 months after the last treatment and then annually.

\subsection{Role of RFA in Barrett's esophagus}

Patients with visible abnormalities in a Barrett's esophagus containing intramucosal carcinoma or high-grade dysplasia may be treated with RFA, but only after endoscopic resection of the intramucosal carcinoma or visible lesion. First, endoscopic resection permits optimal histopathological staging of a lesion, enabling patients with intramucosal carcinoma and a low risk of lymph node involvement to be selected for endoscopic treatment (Gondrie et al., 2008; Peters et al., 2008). Second, RFA should be performed on a flat mucosa to ensure that the uniform ablation depth, as uniquely effected by the HALO system, truly reaches as deep as the muscularis mucosae. 
Patients with Barrett's esophagus with high-grade dysplasia seem to be ideal candidates for RFA, since eradication of their dysplastic Barrett's esophagus may prevent development of intramucosal carcinoma. Proper selection of these patients is, however, of the utmost importance. Patients should have no visible lesions: these require endoscopic resection for optimal staging and treatment.

Studies in the United States on the use of RFA for low-grade dysplasia have shown an excellent efficacy and safety profile (Sharma et al., 2006, 2008; Shaheen et al., 2008), which has led several centers to accept low-grade dysplasia as an indication for RFA treatment. In Europe, low-grade dysplasia is currently treated by RFA only in clinical trials. These differences are mainly driven by cultural approaches; studies comparing the rate of cancer development in patients treated with RFA and patients undergoing surveillance, as well as future studies on molecular and oncogenic markers that may predict malignant progression, may shed more light on which approach is to be preferred in these patients.

Although RFA seems a very promising ablation modality for Barrett's esophagus, there are still some unclear issues that need to be studied further, especially relating to its long-term efficacy. Since the risk of progression to cancer in patients with nondysplastic Barrett's esophagus is small, RFA is still controversial in such patients. Hopes are set on the future development of biological markers for risk stratification to decide which patients with nondysplastic Barrett's esophagus are at risk of malignant progression and would benefit from RFA.

\subsection{Clinical trials}

A number of prospective clinical studies were initiated to evaluate the safety and efficacy of RFA in the whole spectrum of Barrett's esophagus patients: nondysplastic Barrett's esophagus (Sharma et al., 2007; Fleischer et al., 2008), low-grade dysplasia (Sharma et al., 2006, 2008; Shaheen et al., 2008), and intramucosal carcinoma (Gondrie et al., 2008; Westerterp et al., 2005).

In the AIM trial reported by Sharma et al., 102 patients with nondysplastic Barrett's esophagus were included and treated with RFA. In the second phase of the trial, complete eradication of intestinal metaplasia at 12 months was achieved in 48 of 70 subjects (70\%) using only the HALO ${ }^{360}$ system for circumferential ablation (Sharma et al., 2007). Additional ablation of residual's Barrett's esophagus by the HALO ${ }^{90}$ system resulted in complete clearance of intestinal metaplasia in $97 \%$ of patients at 30 months follow-up (Fleischer et al., 2008). None of the patients from the AIM trial presented with esophageal stenosis, and no buried Barrett's glands were found in any of the more than 4000 nonsquamous biopsies obtained during follow-up (Sharma et al., 2007; Fleischer et al., 2008).

In a prospective cohort of 63 patients with low-grade dysplasia $(n=39)$ and high-grade dysplasia $(n=24)$ at the Mayo Clinic with a median follow-up of 24 months, Sharma et al. reported an overall complete response for intestinal metaplasia of $79 \%$ and a complete response for dysplasia of $89 \%$. For the low-grade dysplasia cohort, complete response was $87 \%$ for intestinal metaplasia and $95 \%$ for dysplasia. For the high-grade dysplasia cohort, complete response was $67 \%$ for intestinal metaplasia and $79 \%$ for dysplasia (Sharma et al., 2006). 
For ablation of Barrett's esophagus in patients with low-grade dysplasia and high-grade dysplasia, the strongest evidence that RFA reduces the risk of malignant progression comes from the randomized controlled trial by Shaheen et al. (Shaheen et al., 2009) that was conducted in 19 centers in the United States. A total of 127 patients with dysplastic Barrett's esophagus were randomized to RFA or sham (2:1). In the intention-to-treat analyses, among patients with low-grade dysplasia, complete eradication of dysplasia occurred in $90.5 \%$ of those in the ablation group, as compared with $22.7 \%$ of those in the control group $(\mathrm{P}<0.001)$. Among patients with high-grade dysplasia, complete eradication occurred in $81.0 \%$ of those in the ablation group, as compared with $19.0 \%$ of those in the control group $(\mathrm{P}<0.001)$. Overall, $77.4 \%$ of patients in the ablation group had complete eradication of intestinal metaplasia as compared with $2.3 \%$ of those in the control group $(\mathrm{P}<0.001)$. Patients in the ablation group had less disease progression $(3.6 \%$ vs. $16.3 \%$, $\mathrm{P}=0.03)$ and fewer cancers $(1.2 \%$ vs. $9.3 \%, \mathrm{P}=0.045)$. Patients reported having more chest pain after the ablation procedure than after the sham procedure. In the ablation group, one patient had upper gastrointestinal hemorrhage, and five patients $(6.0 \%)$ had esophageal stricture.

Gondrie et al. reported on a total of 23 patients with high-grade dysplasia and/or intramucosal carcinoma, of whom 13 underwent endoscopic resection of visible lesions prior to RFA (Gondrie et al., 2008). After a median of 1.5 circumferential and 2.6 focal ablation sessions, complete eradication of all dysplasia and intestinal metaplasia was achieved in all patients (100\%). There were no adverse events. An important observation from the studies by Gondrie et al. is the possibility of resecting areas of Barrett's mucosa that persist after multiple RFA sessions. This may be a significant advantage compared to other endoscopic ablation techniques that typically result in submucosal scarring, which makes escape treatment with endoscopic resection complicated. Compared to the $0 \%-56 \%$ stricture rate associated with other endoscopic ablation techniques (Overholt et al., 2003; Peters et al., 2005; Hage et al., 2004; Schulz et al., 2000; Van Laethem et al., 2001), the minimal rate of esophageal stenosis reported in the trials discussed above is encouraging. In addition, RFA does not impair the functional integrity of the esophagus (Beaumont et al., 2007). It has been shown that stepwise circumferential and focal ablation of Barrett's esophagus with highgrade dysplasia results in restoration of normal-appearing neosquamous mucosa without any of the oncogenetic abnormalities present before treatment (Gondrie et al., 2007). These important findings were confirmed in another study suggesting that the neosquamous tissue holds no residual malignant potential (Finkelstein \& Lyday, 2008).

\subsection{Summary}

Current data suggest that RFA is an encouraging modality for eradication of Barrett's esophagus, with many appealing aspects. RFA has been proven to be highly effective in eradicating intestinal metaplasia and its associated dysplasia; it has a low complication rate, preserves the functional integrity of the esophagus, and is relatively easy to apply; and the regenerating neosquamous epithelium is free of the pre-existing oncogenetic alterations. There are, however, still some unanswered questions concerning the optimal use of the $\mathrm{HALO}^{90}$ catheter, the optimal combination of endoscopic resection with RFA, the presence of buried Barrett's glands following RFA, and whether the effect is maintained on the long run. For patients with intramucosal carcinoma and high-grade dysplasia, RFA appears to be 
a valid and less invasive alternative to PDT, APC or esophagectomy, albeit after endoscopic resection of intamucosal carcinoma and visible lesions. For patients with low-grade dysplasia or nondysplastic Barrett's esophagus, RFA treatment is more debatable but justified in some selected patients. Further clinical studies, data from long-term follow-up after RFA, and development of biological markers to predict malignant progression of intestinal metaplasia will elucidate the question of which patients should be treated with RFA for eradication of Barrett's esophagus.

\section{Primary nonsurgical therapy}

There is considerable controversy as to the ideal therapeutic approach for esophageal cancer. Definitive therapy for esophageal cancer is either surgical or nonsurgical. Although the overall results of these two approaches are similar, the patient population selected for treatment with each modality is usually different. For multiple reasons, this results in a selection bias against the nonsurgical group. First, patients with unfavorable prognostic features are more likely selected for treatment with nonsurgical therapy. These features include medical contraindications and primary unresectable or metastatic disease. Second, surgical series report results based on pathologically determined stage, whereas nonsurgical series report results based on clinically determined stage. Pathologic staging has the advantage of excluding some patients with metastatic disease not identified during clinical staging. Third, patients treated without surgery are approached in a palliative rather than a curative fashion. Therefore, the intensity of chemotherapy and the doses of radiation therapy might be suboptimal.

In staging esophageal cancer preoperatively not only CT and EUS are used, but the efficacy of FDG-PET must be emphasized. Studies have examined the effectiveness of PET in the staging of esophageal cancer. After standard staging for esophageal cancer (including CT and endoscopy), undetected metastatic disease was identified by PET in $15 \%$ of patients in the series by Flamen et al (Flamen et al., 2002) and in $20 \%$ of patients in the series by Downey and associates (Downey et al., 2003). Therefore, PET's use is highly encouraged for all patients who are selected for a nonoperative approach.

\subsection{Radiation therapy}

The 1992-1994 Patterns of Care study examined 400 patients treated at 61 academic and nonacademic radiation oncology practices to determine practice patterns in the United States (Coia et al., 2000). During that period, treatment approaches included primary chemoradiation, 54\%; radiation alone, 20\%; preoperative chemoradiation, 13\%; postoperative combined modality therapy, $8 \%$; postoperative radiation, $4 \%$; and preoperative radiation, 1\%. In another study, Patterns of Care analysis from 1996 to 1999, 414 patients who received radiation therapy as part of definitive or adjuvant management at 59 institutions were surveyed (Suntharalingam et al., 2003). Compared with the 1992-1994 survey, more patients underwent EUS staging $(18 \%$ vs. $2 \% ; P<.0001)$ and more patients received preoperative chemoradiation $(27 \%$ vs. $10 \%$; $P=.007)$; preoperative chemoradiation was used more frequently in the subset of patients with adenocarcinoma (46\% vs. $19 \% ; P=$ $.0002)$, and the use of paclitaxel-based chemotherapy increased (22\% vs. $0.2 \% ; P=.001)$. Brachytherapy was used in $6 \%$ of patients. In a similar patterns of care study of 767 patients 
treated in Japan from 1998 to 2001, 220 (28\%) received preoperative or postoperative radiation or both, with or without chemotherapy (Gomi et al., 2003).

The effect of histologic type (adenocarcinoma vs. squamous cell carcinoma) is unclear. At present, the data is conflicting, with some series reporting different results by histologic type but other series reporting no difference. Fortunately, the current Intergroup randomized trials stratify patients by histologic type. Until these data are available and more mature, the impact of histologic type cannot be adequately assessed, and it is reasonable to treat both types of lesions in a similar fashion.

\subsubsection{Radiation therapy alone}

Multiple series have reported the results of external-beam radiation therapy alone for patients with esophageal cancer. Most include patients with unfavorable features such as clinical T4 disease and multiple positive lymph nodes. For instance, in the series of De-Ren, 184 of the 678 patients had stage IV disease (De-Ren, 1989). Overall, the 5-year survival rate for patients treated with conventional doses of radiation therapy alone is $0 \%$ to $10 \%$ (DeRen, 1989; Newaishy et al., 1982; Okawa et al., 1989). The use of radiation therapy as a potentially curative modality requires doses of at least $50 \mathrm{~Gy}$ at 1.8 to $2.0 \mathrm{~Gy} /$ fraction. Shi and colleagues reported a 33\% 5-year survival rate with the use of late-course accelerated fractionation to a total dose of $68.4 \mathrm{~Gy}$ (Shi et al., 1999). However, in the radiation-therapyalone arm of the RTOG 85-01 trial in which patients received 64 Gy at 2 Gy/d with modern techniques, all patients were dead of their disease by 3 years (Herskovic et al., 1992; AlSarraf et al., 1997).

There is limited experience in the use of radiation therapy alone for patients with superficial (Seki et al., 2001) or clinically determined T1 disease (Nemoto et al., 2002). The trial by Sykes et al. was limited to 101 patients (90\% with squamous cell carcinoma) with tumors smaller than $5 \mathrm{~cm}$ who received 45 to $52.5 \mathrm{~Gy}$ in 15 to 16 fractions. The 5 -year survival was $20 \%$ (Sykes et al., 1998). Overall, these data indicate that radiation therapy alone should be reserved for palliation or for patients who are medically unable to receive concurrent chemoradiotherapy. The results of definitive chemoradiation are more favorable, and it remains the standard of care.

\subsubsection{Radiation therapy techniques}

Radiation field design for esophageal cancer requires careful techniques in order to achieve optimal results (Phillips et al., 1998). There are a number of sensitive organs that, depending on the location of the primary tumor, may be in the radiation field. These include skin, spinal cord, lung, heart, intestine, stomach, kidney, and liver. Minimizing the dose to these vital structures while delivering an adequate dose to the primary tumor and local-regional lymph nodes requires patient immobilization and CT-based treatment planning for organ identification, lung correction, and development of dose-volume histograms. Although CT can accurately identify adjacent organs and structures, it may be limited in defining the extent of the primary tumor. Among radiation oncologists, there is significant inconsistency in defining the planning target volume, both in the transverse and longitudinal dimensions. Therefore, in addition to a CT scan, it is always helpful to obtain a barium swallow test at 
the time of radiation therapy simulation. The integration of other imaging modalities such as EUS, PET, and magnetic resonance imaging into radiation treatment planning remains under investigation.

In one study reported by Tai et al., 12 Canadian radiation oncologists drew cervical esophagus target volumes based on the RTOG 94-05 protocol design both before and after a one-on-one training session (Tai et al., 2002). Pretraining and posttraining survey revealed less variability in the longitudinal positions of the target volumes after training, which illustrates the importance of specialized training. In another study, Nutting et al. compared two-phase conformal radiotherapy with intensity-modulated radiotherapy (IMRT) in five patients who received 55 Gy of radiation plus concurrent chemotherapy (Nutting et al., 2001). Treatment plans using both techniques were carried out and were compared using dose-volume histograms and normal tissue complication probabilities. The IMRT using nine equispaced fields did not add any improvement over conformal radiation because the larger number of fields in the IMRT plan distributed a low dose over the entire lung. In contrast, IMRT using four fields equal to the conformal fields offered an improvement in lung sparing.

In the treatment of esophageal cancer, radiation oncologists usually treat tumors at or above the carina as a cervical primary and the supraclavicular nodes are included in the radiation field. Tumors below the carina but not extending to the gastroesophageal junction are considered mid-esophageal, and the radiation field does not include the supraclavicular or celiac nodes. Tumors that involve the gastroesophageal junction are considered distal and the celiac nodes are included. This simple and practical definition is helpful in designing radiation therapy fields.

The standard radiation dose for patients selected for curative nonoperative chemoradiation is $50.4 \mathrm{~Gy}$ at $1.8 \mathrm{~Gy} /$ fraction. The radiation field should include the primary tumor with 5$\mathrm{cm}$ superior and inferior margins and 2-cm lateral margins. The primary local-regional lymph nodes should receive the same dose.

For cervical esophageal tumors, patients are placed supine. Field designs include a threefield plan (two anterior oblique fields and a posterior field) or, more commonly, anteroposterior-posteroanterior to 39.6 to 41.4 cGy followed by a left or right opposed oblique pair with photons plus an electron boost to the contralateral supraclavicular area, both to a total dose of 50.4 Gy. For mid-esophageal tumors, patients are placed prone to help exclude the spinal cord from the radiation field and a four-field design is used (anteroposterior, posteroanterior, and opposed lateral fields). For distal tumors, patients are treated supine using the same four-field technique. Caution should be taken to exclude as much of the normal stomach as possible, especially if the patient is receiving radiation preoperatively. CT-based three-dimensional treatment planning should be performed, and all fields should be treated each day. Dose-volume histograms help guide the radiation oncologist in choosing a radiation plan that minimizes the loss of normal organ function.

In the palliative setting there are a variety of radiation treatment regimens. Because the goal is rapid palliation of symptoms, the most common approach is to treat anteroposteriorly and posteroanteriorly, including the primary tumor with $2-\mathrm{cm}$ margins, in ten 3-Gy fractions to a total dose of $30 \mathrm{~Gy}$. 
The most critical normal structures that lie in proximity to the esophagus are the spinal cord, heart, lungs, and kidneys. When radiation is combined with chemotherapy, the radiation fractionation should be $1.8 \mathrm{~Gy} / \mathrm{d}$. The spinal cord dose should not exceed $45 \mathrm{~Gy}$. All fields should be treated each day. Doses to the heart, lungs, and kidneys depend to a large extent on the volume of these organs in the treatment field. Dose-volume histograms are the most effective way to modify treatment techniques to decrease the acute and long-term radiationrelated toxicity. In the rare situations when whole heart irradiation is needed, the dose should be limited to 25 to $30 \mathrm{~Gy}$. In the thorax, radiation fields frequently include substantial volumes of lung, especially with oblique or lateral fields. Decreased pulmonary function occurs after irradiation, particularly if large volumes of lung are exposed to doses greater than 20 Gy. There is progressive decreased ventilatory and diffusing capacity as a result of endothelial degeneration and interstitial fibrosis. Fields that include such substantial volumes of lung should be limited to $20 \mathrm{~Gy}$. Except for the spinal cord, it is acceptable for small volumes of normal tissue in immediate proximity to the esophagus to receive doses as high as 60 Gy. However, because the standard total dose of radiation is $50.4 \mathrm{~Gy}$, this degree of inhomogeneity should be uncommon. Fortunately, even with tumors as distal as the gastroesophageal junction, there is a limited amount of liver and kidney in the treatment fields.

\subsection{Combined chemoradiation}

There are multiple single-arm, nonrandomized trials of chemoradiation alone and they have included patients with disease at different stages (Seitz et al., 1990; Izquiredo et al., 1993; Coia et al., 1991;Valerdi et al., 1994; Poplin et al., 1996). Few series examined patients with T1 or T2 disease (Seki et al., 2001; Coia et al., 1991; Nemoto et al., 2001). In the series reported by Coia and associates, patients received $60 \mathrm{~Gy}$ of radiation therapy concurrently with intravenous 5-FU and mitomycin C (Coia et al., 1991). For stage I and II disease, the local failure rate was $25 \%$, the 5 -year actuarial local relapse-free survival and overall survival were $70 \%$ and $30 \%$ respectively.

Thirteen randomized trials compared radiation therapy alone with chemoradiation. Major trials are summarized in Table 1.

In a pooled analysis of these trials (Wong \& Malthaner 2006, 2010), concomitant chemoradiotherapy provided significant overall reduction in mortality at 1 and 2 years. The mortality in the control arms was $62 \%$ and $83 \%$ respectively. Combined chemoradiotherapy provided an absolute reduction of mortality by $7 \%$ and $7 \%$ respectively. In addition, there was a reduction in the overall local recurrence rate. The local recurrence rate for the control arms was in the order of $68 \%$. Combined chemoradiothrapy provided an absolute reduction of local recurrence rate of $12 \%$. However, chemoradiation was associated with a significant increase in adverse effects, including life-threatening toxicities.

In the ECOG EST-1282 trial (Araujo et al., 1991),patients who received combined modality therapy had a significantly increased median survival compared with those receiving radiation alone (15 months vs. 9 months; $P=.04$ ) but experienced no improvement in 5-year survival ( $9 \%$ vs. $7 \%$ ). However, this was not a pure nonsurgical trial because approximately $50 \%$ of patients in each arm underwent surgery after receiving $40 \mathrm{~Gy}$ of radiation. The operative mortality was $17 \%$. 


\begin{tabular}{|c|c|c|c|c|}
\hline Series & $\begin{array}{l}\text { Patients } \\
\text { (n) }\end{array}$ & $\begin{array}{c}\text { Overall } \\
\text { Survival (\%) }\end{array}$ & $\begin{array}{l}\text { Median } \\
\text { Survival } \\
\text { (months) }\end{array}$ & $\begin{array}{c}\text { Local } \\
\text { Failure }(\%)\end{array}$ \\
\hline \multicolumn{5}{|c|}{$\begin{array}{l}\text { Herskovic et al. (RTOG) } \\
\text { (Herskovic et al., 1992; Al-Sarraf } \\
\text { et al., 1997; Cooper et al., 1999) }\end{array}$} \\
\hline Radiation alone & 62 & 0 at 5-yr & 9 & 68 \\
\hline Combined therapy & 61 & $\begin{array}{l}27 \text { at } 5-y r \\
22 \text { at } 8-y r\end{array}$ & 14 & 47 \\
\hline Combined therapy & 69 & NR & 17 & 52 \\
\hline \multicolumn{5}{|c|}{$\begin{array}{l}\text { Araujo et al. (NCI Brazil) } \\
\text { (Araujo et al., 1991) }\end{array}$} \\
\hline Radiation alone & 31 & 6 at $5-y r$ & & 84 \\
\hline Combined therapy & 28 & 16 & & 61 \\
\hline \multicolumn{5}{|l|}{$\begin{array}{l}\text { Roussel et al. (EORTC) } \\
\text { (Roussel et al., 1988) }\end{array}$} \\
\hline Radiation alone & 69 & 6 at 3-yr & & \\
\hline Combined therapy & 75 & 12 & & \\
\hline \multicolumn{5}{|c|}{$\begin{array}{l}\text { Nygaard et al. (Scandinavia) } \\
\text { (Nygaard et al., 1992) }\end{array}$} \\
\hline Radiation alone & 51 & 6 at $3-y r$ & & \\
\hline Combined therapy & 46 & 0 & & \\
\hline \multicolumn{5}{|c|}{$\begin{array}{l}\text { Smith et al. (ECOG-EST 1282) } \\
\text { (Smith et al., 1998) }\end{array}$} \\
\hline Radiation alone & 60 & 7 at 5-yr & 9 & \\
\hline Combined therapy & 59 & 9 & 15 & \\
\hline \multicolumn{5}{|l|}{$\begin{array}{l}\text { Slabber et al. (Pretoria) } \\
\text { (Slabber et al., 1998) }\end{array}$} \\
\hline Radiation alone & 36 & & 5 & \\
\hline Combined therapy & 34 & & 6 & \\
\hline
\end{tabular}

Table 1. Randomized Trials of Radiation Therapy versus Combined Modality Therapy for Esophageal Cancer.

The trial that was designed to deliver adequate doses of systemic chemotherapy with concurrent radiation therapy was the RTOG 85-01 trial reported by Herskovic et al. (Herskovic et al., 1992; Al-Sarraf et al., 1997; Cooper et al., 1999). This Intergroup trial primarily included patients with squamous cell carcinoma. Patients received four cycles of 5 -FU (1000 mg/m²/24 h 44 days) and cisplatin $\left(75 \mathrm{mg} / \mathrm{m}^{2}\right.$ on day 1$)$. Radiation therapy (50 Gy at $2 \mathrm{~Gy} / \mathrm{d}$ ) was given concurrently with day 1 of chemotherapy. After radiation therapy is finished, cycles 3 and 4 of chemotherapy were delivered every 3 weeks (weeks 8 and 11) rather than every 4 weeks (weeks 9 and 13). This intensification may explain, in part, why only $50 \%$ of the patients finished all four cycles of the chemotherapy. The control arm was 
given radiation therapy alone, albeit at a higher dose (64 Gy) than the chemoradiation arm. Patients who received chemoradiation had a significant improvement in median survival (14 months vs. 9 months) and 5 -year survival $(27 \%$ vs. $0 \%$; $P<.0001)(81)$. There was a clear plateau in the survival curve. Minimum follow-up was 5 years, and the 8 -year survival was $22 \%$ (Cooper et al., 1999). Histologic type did not significantly influence the results: $21 \%$ of patients with squamous cell carcinomas $(n=107)$ were alive at 5 years compared with $13 \%$ of patients with adenocarcinoma $(n=23)$ ( $P$ was not significant). Although African Americans had larger primary tumors and all were squamous cell cancers, there was no difference in their survival compared with whites (Streeter et al., 1999). The incidence of local failure as the first site of failure (defined as local persistence or recurrence) was also decreased in the combined modality arm (47\% vs. $65 \%)$. The protocol was closed early due to the positive results; however, after this early closure, an additional 69 eligible patients were treated with the same chemoradiation regimen. In this nonrandomized combined modality group, the 5 -year survival was $14 \%$ and local failure was $52 \%$.

Chemoradiation not only improves the results compared with radiation alone but also is associated with a higher incidence of toxicity. In the 1997 report of the RTOG 85-01 trial, patients who received chemoradiation had a higher incidence of acute grade 3 toxicity $(44 \%$ vs. $25 \%)$ and acute grade 4 toxicity $(20 \%$ vs. $3 \%)$ compared with those who received radiation therapy alone. Including the one treatment-related death $(2 \%)$, the incidence of total acute grade $3+$ toxicity was $66 \%$ (81). The 1999 report examined late toxicity. The incidence of late grade $3+$ toxicity was similar in the combined modality arm and in the radiation-alone arm (29\% vs. $23 \%)(94)$. However, grade $4+$ toxicity remained higher in the combined modality arm (10\% vs. $2 \%)$. Interestingly, the nonrandomized chemoradiation group experienced a similar incidence of late grade $3+$ toxicity $(28 \%)$ but a lower incidence of grade 4 toxicity $(4 \%)$, and there were no treatment-related deaths.

Based on the positive results from the RTOG 85-01 trial, the standard nonsurgical treatment for esophageal carcinoma became chemoradiation. However, the local failure rate in the RTOG 85-01 chemoradiation arm was still high at 45\%, and there is room for improvement. Therefore, new approaches such as intensification of chemoradiation and escalation of the radiation dose have been developed in an attempt to help improve these results.

\subsection{Comparison of definitive chemoradiation and surgery}

There are a number of trials comparing preoperative chemoradiation with surgery alone. However, there is limited data regarding the direct comparison of the two standard treatments for nonmetastatic esophageal cancer: concurrent chemoradiation and surgery alone. The positive results of RTOG $85-01$, demonstrating a $27 \% 5$-year survival rate for patients treated with definitive chemoradiation compared with no 5-year survival after treatment with radiotherapy alone, is a major advance. This treatment option has influenced the selection of patients for nonsurgical management because it provides an acceptable alternative for restoring swallowing function in patients with locally advanced disease for whom surgery would be mainly palliative.

For patients with earlier-stage disease that appears resectable, definitive chemoradiation may also be appropriate treatment; however, prospective randomized trials comparing this approach with surgery, stratified by stage, have yet to be performed. Nonetheless, some 
series suggest that the nonsurgical approach offers a survival rate that is the same or better than that achievable with surgery alone. For example, the median survival time and 5-year survival rate were 14 months and $27 \%$, respectively, in the chemoradiation arm of RTOG 8501 and 20 months and 20\%, respectively, in INT 0122 (Minsky et al., 1999). In comparison, the median survival in the surgical control arm of the Dutch trial reported by Kok et al (Kok et al., 1997) was 11 months, and the median survival time and 5-year survival rate in the surgical control arm of INT 0113 were 16 months and $20 \%$, respectively. Likewise, the local failure rates were similar. The incidence of local failure as the first site of failure was $45 \%$ in RTOG 85-01 and 39\% in INT 0122. Although local failure as the first site of failure was 31\% in INT 0113, this analysis was limited to patients who underwent a complete resection with negative margins (R0 resection). Because an additional 30\% of patients had residual local disease, if one were to score these patients also as having locally persistent disease (as was done in the RTOG 85-01 analysis), the comparable local failure rate with surgery alone would be $30 \%+31 \%=61 \%$. The treatment-related mortality rates were also similar $(2 \%$ in RTOG 85-01, 9\% in INT 0122, and 6\% in INT 0113).

Chiu et al. (Chiu et al., 2005) conducted a prospective randomized trial that compared the efficacy and survival outcome of chemoradiation with that of esophagectomy as a curative treatment. In this multicenter trial, 80 patients with potentially resectable squamous cell carcinoma of the mid or lower thoracic esophagus were randomized to esophagectomy or chemoradiotherapy. Patients treated with chemoradiotherapy received continuous 5fluorouracil infusion ( $200 \mathrm{mg} / \mathrm{m} 2 /$ day) from day 1 to 42 and cisplatin $(60 \mathrm{mg} / \mathrm{m} 2)$ on days 1 and 22. The tumor and regional lymphatics were concomitantly irradiated to a total of 50-60 Gy. Salvage esophagectomy was performed for incomplete response or recurrence. Forty-four patients received standard esophagectomy, whereas 36 were treated with chemoradiotherapy. Median follow-up was 6.9 months. There was no difference in either survival or disease-free survival between the two groups. Patients treated with surgery had a slightly higher proportion of recurrence in the mediastinum, whereas those treated with chemoradiation sustained a higher proportion of recurrence in the cervical or abdominal regions.

In summary, the local failure, survival, and treatment-related mortality rates for nonsurgical and surgical therapies are similar. Although the results are comparable, it is clear that both the nonsurgical and surgical approaches have limited success.

\subsection{Necessity for surgery after chemoradiation}

Two trials examined whether surgery is necessary after chemoradiation. The Federation Francaise de Cancerologie Digestive (FFCD) trial addresses the issue of whether patients who respond midway through chemoradiation should continue with the treatment or undergo surgery (Bedenne et al., 2007). The German Oesophageal Cancer Study Group examined the question of whether chemoradiation followed by surgery is equivalent to nonoperative chemoradiation (Stahl et al., 2005).

In the FFCD 9102 trial, all 445 patients with clinically resectable T3 to 4 N0 to 1 M0 squamous cell carcinoma or adenocarcinoma of the esophagus received chemoradiation; however, the randomization was limited to patients who responded to initial chemoradiation. Patients initially received two cycles of 5-FU and cisplatin plus concurrent radiation (either 46 Gy at 2 Gy/d or a split-course regimen of 15 Gy in weeks 1 and 3) (Bedenne et al., 2007). The 259 
patients who had at least a partial response were then randomly assigned to receive surgery or additional chemoradiation, which included three cycles of 5-FU and cisplatin, plus concurrent radiation (either $20 \mathrm{~Gy}$ at $2 \mathrm{~Gy} / \mathrm{d}$ or split-course $15 \mathrm{~Gy}$ ). There was no significant difference in 2-year survival (34\% for those undergoing surgery vs. $40 \%$ for those receiving chemoradiation; $P=.56)$ or median survival (18 months for the surgery group vs. 19 months for the chemoradiation group). Two-year local control rate was $66.4 \%$ in arm A compared with 57.0\% in $\operatorname{arm} \mathrm{B}$, and stents were less required in the surgery arm $(5 \%$ in $\operatorname{arm} \mathrm{A} v 32 \%$ in $\operatorname{arm} \mathrm{B} ; \mathrm{P}<$ $.001)$. The 3-month mortality rate was $9.3 \%$ in arm A compared with $0.8 \%$ in arm $B(P=.002)$. Cumulative hospital stay was 68 days in arm A compared with 52 days in arm $\mathrm{B}(\mathrm{P}=.02)$. The data suggest that patients who initially respond to nonoperative chemoradiation should complete chemoradiation rather than stop and undergo surgery. As measured using the Spitzer index, there was no difference in global quality of life; however, a significantly greater decrease in quality of life was observed in the postoperative period in the surgery arm (7.52 vs. 8.45; $P<.01$ ) (Bonnetain et al., 2006).

The German Oesophageal Cancer Study Group compared preoperative chemoradiation followed by surgery with chemoradiation alone (Stahl et al., 2005). In this trial, 177 patients with uT3-4N0-1M0 squamous cell cancers of the esophagus were randomly assigned to receive preoperative therapy (three cycles of 5-FU, leucovorin, etoposide, and cisplatin, followed by concurrent etoposide and cisplatin, plus $40 \mathrm{~Gy}$ of radiation) followed by surgery or chemoradiation alone (the same chemotherapy regimen, but the radiation dose was increased to $60 \mathrm{~Gy}$ ). Despite an improvement in 2-year progression free survival for those who were randomly assigned to receive preoperative therapy followed by surgery compared with those receiving chemoradiation alone (64\% vs.41\%), there was no significant difference in overall survival.. The results of this trial were updated at ASCO in 2008 which showed no significant improvement in 5-year survival between the two arms but persistent benefit of local control with the surgery arm. Although the difference in the radiation dose in the two arms makes the interpretation of the data difficult, there does not appear to be a benefit to surgery after nonoperative chemoradiation.

\subsection{Tumor markers and predictors of response to chemoradiation}

It would be important to predict which tumors have a higher likelihood of responding to radiation or chemoradiation. In 38 patients with squamous cell carcinoma who received chemoradiation with or without surgery, tumors without p53 expression and tumors with weak Bcl-X L expression showed a higher response to chemotherapy (56\% and 53\%, respectively) than tumors positive for p53 or with strong Bcl- $X_{L}$ expression ( $30 \%$ and $32 \%$, respectively; $P$ not significant) (Sarbia et al., 1998). After preoperative chemoradiation, patients with p53-negative tumors had a significantly better mean survival than those with p53-positive tumors (31 months vs. 11 months; $P=.0378$ ). By multivariate analysis, Pomp et al. found that overexpression of p53 resulted in a decrease in survival in 69 patients with squamous cell carcinoma or adenocarcinoma treated with radiation alone (Pomp et al., 1998). In one study, there was a correlation between decreasing levels of four phospholipids and increasing T stage and grade (Merchant et al., 1999).

Kishi and associates reported that, of 77 patients treated with chemoradiation for squamous cell cancer, those with p53- and metallothionein-positive tumors had a poor response to 
treatment, whereas strong expression of CDC25B was associated with a good response (Kishi et al., 2002). In 73 patients with T2 to 4 M0 esophageal cancer treated with 60 Gy of radiation plus 5-FU and cisplatin, Hironaka et al. examined pretreatment biopsy specimens for a variety of markers, including p53, Ki-67, EGF receptor, cyclin D1, vascular endothelial growth factor, microvessel density (MVD), thymidylate synthase, dihydropyrimidine dehydrogenase, and glutathione S-transferase (Hironaka et al., 2002). By multivariate analysis MVD, T stage, and performance status were independent prognostic variables $(P=$ $.002, .02$, and .02 , respectively). Patients with high-MVD tumors had a better 3-year survival rate than those with low-MVD tumors $(61 \%$ vs. $33 \% ; P=.02)$. Morita et al. found that patients with lymphocyte infiltration around the tumor had a 5-year survival rate of $46 \%$ to $76 \%$ compared with $28 \%(P<.05)$ in patients whose tumors did not have lymphocytic infiltration (Morita et al., 2001). With the further discovery and understanding of various tumor suppressor genes, these data may be used to help select patients for chemoradiation.

\subsection{Intensification of chemoradiation}

The phase II Intergroup trial 0122 [ECOG PE289/RTOG 90-12] was designed to intensify treatment in the RTOG 85-01 combined modality arm (102). Both the chemotherapy and radiation therapy in INT 0122 were intensified as follows: (1) the 5-FU continuous infusion $\left(1000 \mathrm{mg} / \mathrm{m}^{2} / 24\right.$ hours) was increased from 4 days to 5 days, (2) the total number of cycles of chemotherapy was increased from four to five cycles, (3) three cycles of full-dose neoadjuvant 5-FU and cisplatin were delivered before the start of chemoradiation, and (4) the radiation dose was increased from 50 Gy to $64.8 \mathrm{~Gy}$. In this study, 38 patients with squamous cell carcnoma were eligible. The primary tumor response rate was as follows: $47 \%$ complete response, $8 \%$ partial response, and 3\% stable disease (Kelsen et al., 1990). The first site of clinical treatment failure was local in $39 \%$ and distant in $24 \%$. In the total patient group, there were six deaths during treatment, four of which were treatment related $(9 \%$ of 45 patients). The median survival time was 20 months and the 5-year actuarial survival rate was $20 \%$. Unfortunately, this intensive neoadjuvant approach did not appear to offer a benefit compared with conventional doses and techniques of chemoradiation. Similar toxicities were reported by Ishikura et al. for 139 patients with squamous cell cancers treated with 5-FU, cisplatin, and 60 Gy of radiation (Ishikura et al., 2003).

A limited number of phase I and II trials have tested the use of neoadjuvant chemotherapy before radiation therapy or chemoradiation. Valerdi et al. reported the results for 40 patients with clinical stage II and III squamous cell cancers who received two cycles of neoadjuvant cisplatin, vindesine, and bleomycin (days 1 and 29) followed by 60 Gy of radiation (Valerdi et al., 1994). In contrast with the INT 0122 trial, no chemotherapy was delivered with the radiation therapy. The pathologically determined complete response rate was $53 \%$. After a median follow-up of 78 months, the local failure rate was $62 \%$, the median survival time was 11 months, and the 5-year actuarial survival rate was $15 \%$. These results are similar to those obtained for the RTOG 85-01 combined modality arm with the exception of the higher treatment-related death rate of $5 \%$.

Using a five-drug neoadjuvant regimen, Roca and colleagues treated 55 patients (54 with squamous cell cancer) with bolus cisplatin, 5-FU, leucovorin, bleomycin, and mitomycin C for 15 days followed by 60 Gy of radiation plus concurrent chemotherapy with 5-FU, 
leucovorin, and cisplatin (Roca et al., 1996). No maintenance chemotherapy was delivered. Patients with lesions at all anatomic sites within the esophagus were eligible and $53 \%$ had clinical stage III disease. Although the treatment-related mortality was only $4 \%$ and the 3year survival was $35 \%$, local failure as a component of failure was $42 \%$, which was similar to the $45 \%$ rate reported in the RTOG 85-01 chemoradiation arm.

Recent trials using newer regimens for neoadjuvant chemotherapy such as paclitaxel and cisplatin (Bains et al., 2002) or CPT-11 and cisplatin (Ilson et al., 2003) before the start of chemoradiation have reported more favorable results. Bains and associates reported that, of 38 patients who presented with dysphagia, $92 \%$ had relief after the completion of two cycles (weeks 1 and 4) of neoadjuvant paclitaxel $\left(175 \mathrm{mg} / \mathrm{m}^{2}\right.$, 3-hour infusion) and cisplatin (75$\mathrm{mg} / \mathrm{m}^{2}$ bolus) (Bains et al., 2002). Similar results have been reported by Ilson et al. for 19 patients who received two cycles of neoadjuvant CPT-11 $\left(65 \mathrm{mg} / \mathrm{m}^{2}\right)$ plus cisplatin $(30$ $\mathrm{mg} / \mathrm{m}^{2}$ ) weeks 1, 2, 4, and 5 before the start of chemoradiation (Ilson et al., 2003). Treatment was well tolerated with no grade $3+$ nonhematologic toxicity, and only $5 \%$ of patients required a feeding tube. Of the 16 patients who presented with dysphagia, $81 \%$ had dysphagia relief after the completion of neoadjuvant chemotherapy.

Another potential advantage of neoadjuvant chemotherapy is the early identification of those patients who may or may not respond to the chemotherapeutic regimen being delivered. Ott et al. performed FDG-PET in 35 patients with adenocarcinoma of the gastroesophageal junction or stomach 2 weeks after the start of cisplatin, 5-FU, and leucovorin neoadjuvant chemotherapy, which was followed by surgery; results of the FDGPET scan were able to predict which patients showed a response to the full course of chemotherapy, as judged from the surgical specimens (Ott et al., 2003). Although this study was investigational, if the nonresponders can be identified early, changing the chemotherapeutic regimen may be helpful.

In summary, although the early trials primarily using neoadjuvant regimens based on 5-FU and cisplatin did not suggest a benefit, more recent trials using paclitaxel- and CPT-11based regimens reveal higher response rates resulting in improvement of dysphagia.

\subsection{Intensification of the radiation dose}

Another approach to the dose intensification of chemoradiation is increasing the radiation dose above $50.4 \mathrm{~Gy}$. There are two methods by which to increase the radiation dose to the esophagus: brachytherapy and external-beam radiation therapy.

\subsubsection{Brachytherapy}

Intraluminal brachytherapy allows the escalation of the dose to the primary tumor while protecting the surrounding structures such as the lung, heart, and spinal cord (Armstrong, 1993). A radioactive source is placed intraluminally via bronchoscopy or a nasogastric tube. Brachytherapy has been used both as primary therapy (usually as a palliative modality)(Moni et al., 1996; Sur et al., 1992, 1998; Jager et al., 1995; Maingon et al., 2000) and as boost after external-beam radiation therapy or combined modality therapy (Armstrong, 1993; Calais et al., 1997; Akagi et al., 1999; Schraube et al., 1997; Okawa et al., 1999). It can be delivered either by high dose rate or low dose rate (Caspers et al., 1993). Although there are 
technical and radiobiologic differences between the two dose rates, there are no clear therapeutic advantages for either.

Studies that combine brachytherapy with external-beam radiation therapy or chemoradiation report results similar to those for conventional chemoradiation. Calais et al. reported a local failure rate of $43 \%$ and a 5-year survival of $18 \%$ (Calais et al., 1997). Even for a more favorable subset of patients with clinical T1 to T2 disease, Yorozu et al. reported a local failure rate of $44 \%$ and a 5-year survival of $26 \%$ (Yorozu et al., 1999).

In the RTOG 92-07 trial, 75 patients with squamous cell cancers (92\%) or adenocarcinomas $(8 \%)$ of the esophagus received the RTOG 85-01 combined modality regimen (5-FU, cisplatin, 50 Gy of radiation) followed by a boost during cycle 3 of chemotherapy with either low dose-rate or high dose-rate intraluminal brachytherapy (Gaspar et al., 1997). Due to low accrual rate, the low dose-rate option was discontinued and the analysis was limited to patients who received the high dose-rate treatment. High dose-rate brachytherapy was delivered in weekly fractions of 5 Gy during weeks 8, 9, and 10. Due to the development of several fistulas, the fraction delivered at week 10 was discontinued. Although the complete response rate was $73 \%$, at a median follow-up of only 11 months, rate of local failure as the first site of failure was $27 \%$. Rates of acute toxicity were $58 \%$ for grade 3, $26 \%$ for grade 4 , and $8 \%$ for grade 5 (treatment-related death). The cumulative incidence of fistula was $18 \%$ per year and the crude incidence was $14 \%$. Of the six treatment-related fistulas, three were fatal. Given the significant toxicity, this treatment approach should be used with caution.

The American Brachytherapy Society has developed guidelines for esophageal brachytherapy (Gaspar et al., 1997). Its recommendations include the following. For patients treated in the curative setting brachytherapy should be limited to tumors $10 \mathrm{~cm}$ or less with no evidence of distant metastasis. Contraindications include tracheal or bronchial involvement, cervical esophagus location, or stenosis that cannot be bypassed. The applicator should have an external diameter of 6 to $10 \mathrm{~cm}$. If combined modality therapy is used (defined as 5-FU-based chemotherapy plus 45 to 50 Gy of radiation) the recommended doses of brachytherapy are $10 \mathrm{~Gy}$ in two weekly fractions of 5 Gy each for high dose rate and $20 \mathrm{~Gy}$ in a single fraction at 4 to $10 \mathrm{~Gy} / \mathrm{h}$ for low dose rate. The doses should be prescribed to $1 \mathrm{~cm}$ from the source. Finally, brachytherapy should be delivered after the completion of external-beam radiation therapy and not concurrently with chemotherapy.

In summary, for patients treated in the curative setting, the addition of brachytherapy does not appear to improve the results compared with those for radiation therapy or combined modality therapy alone. Therefore, although it seems reasonable to assume that adding intraluminal brachytherapy to radiation or combined modality therapy would provide an additional benefit, whether such a benefit exists remains unclear.

\subsubsection{External-beam therapy}

There are a limited number of phase II trials examining patient tolerance for external-beam radiation doses of $60 \mathrm{~Gy}$ or more when delivered concurrently with chemotherapy. In an analysis performed by Coia and associates, the results for 90 patients with clinical stage I to IV squamous cell carcinomas and adenocarcinomas of the esophagus were reported (Coia et 
al., 1991). The incidence of grade 3 toxicity was $22 \%$ and of grade 4 toxicity was $6 \%$. There were no treatment-related deaths.

Calais et al. reported the results for 53 patients with clinically unresectable disease who received 5-FU, cisplatin, and mitomycin C plus 65 Gy of radiation (Calais et al., 1994). The full dose of radiation could be delivered in $96 \%$ of patients. The incidence of World Health Organization grade $3+$ toxicity was $30 \%$ and the overall 2 -year survival rate was $42 \%$. It should be noted that the chemotherapy in this trial was not delivered at doses adequate to treat systemic disease. Because almost all patients in both the INT 0122 trial and the Calais trials ( $96 \%$ and $94 \%$, respectively) who started radiation therapy were able to complete the full dose (64.8 to $65.0 \mathrm{~Gy})$, this higher dose of radiation was used in the experimental arm of the Intergroup esophageal trial INT 0123 (RTOG 94-05). The INT 0123 trial (Minsky et al., 2002) was the follow-up to RTOG 85-01. In this trial, patients with either squamous cell carcinoma or adenocarcinoma who were selected for nonsurgical treatment were randomly assigned to receive a slightly modified RTOG 85-01 combined modality regimen with 50.4 Gy of radiation versus the same chemotherapy with $64.8 \mathrm{~Gy}$ of radiation). The modifications to the original RTOG 85-01 chemoradiation arm includes (1) using 1.8-Gy fractions to 50.4 Gy rather than 2-Gy fractions to $50 \mathrm{~Gy}$; (2) treating with 5-cm proximal and distal margins for $50.4 \mathrm{~Gy}$ rather than treating the whole esophagus for the first $30 \mathrm{~Gy}$ followed by a cone down with $5 \mathrm{~cm}$ margins to $50 \mathrm{~Gy}$; (3) cycle 3 of 5-FU and cisplatin did not begin until 4 weeks after the completion of radiation therapy rather than 3 weeks after; and (4) cycles 3 and 4 of chemotherapy were delivered every 4 weeks rather than every 3 weeks. INT 0123 was closed to accrual in 1999 after an interim analysis revealed that it was unlikely that the high-dose arm would achieve superior survival compared with the standard-dose arm. For the 218 eligible patients, there was no significant difference in median survival time (13.0 months vs. 18.1 months) or 2-year survival rate (31\% vs. $40 \%$ ) between the high-dose and standard-dose arms (Minsky et al., 2002) Although 11 treatment-related deaths occurred in the high-dose arm compared with 2 in the standard-dose arm, 7 of the 11 deaths occurred in patients who had received 50.4 Gy or less. To help determine if this unexplained increase in treatment-related deaths in the high-dose arm was the factor responsible for the inferior survival rate, a separate survival analysis was performed that included only patients who received the assigned dose of radiation. Despite this biased analysis, there was still no survival advantage for the high-dose arm. Although the crude incidence of local failure or persistence of local disease (or both) was lower in the high-dose arm than in the standarddose arm (50\% vs. $55 \%)$, as was the incidence of distant failure ( $9 \%$ vs. $16 \%)$, these differences did not reach statistical significance. At 2 years, the cumulative incidence of local failure was $56 \%$ for the high-dose arm versus $52 \%$ for the standard-dose arm $(P=.71)$. Therefore, based on results of the INT 0123 trial, the standard dose of external-beam radiation remains $50.4 \mathrm{~Gy}$. The modifications to the original RTOG 85-01 chemoradiation arm outlined earlier did not adversely affect the local control or survival rate in the control arm of INT 0123. Therefore, the radiation doses and field design used in the control arm of INT 0123 should be used.

Radiation can be intensified not only by increasing the total dose but also by using accelerated fractionation or hyperfractionation. Selected series using the latter approach for radiotherapy given as primary treatment (without surgery) are listed in Table 2. 


\begin{tabular}{|c|c|c|c|c|c|c|}
\hline Series & No. & $\begin{array}{l}\text { Histologic } \\
\text { Type }\end{array}$ & Treatment & $\begin{array}{l}\text { Local } \\
\text { Control }\end{array}$ & Survival & $\begin{array}{c}\text { Grade 3+ } \\
\text { Toxicity }\end{array}$ \\
\hline $\begin{array}{l}\text { Girinsky et al. } \\
\text { (1997) }\end{array}$ & 88 & - & $\begin{array}{l}65 \text { Gy (2Gy Bid) } \\
+/- \\
5 \text { FU/Cisplatin }\end{array}$ & $48 \% 3-y$ & $12 \% 3-y$ & $13 \%$ \\
\hline \multirow{2}{*}{$\begin{array}{l}\text { Jeremic et al. } \\
(1998)\end{array}$} & 28 & Squamous & 54 Gy (1.5 Gy Bid) & $71 \%$ & $29 \% 5-y$ & $50 \%$ \\
\hline & & & $5 \mathrm{FU}+$ Cisplatin $\times 4$ & & & \\
\hline \multirow[t]{2}{*}{$\begin{array}{l}\text { Wang et al. } \\
\text { (2002(randomized) }\end{array}$} & 101 & Squamous & 66 Gy (1.5 Gy Bid)vs. & $56 \% 3-y$ & $38 \% 3-y$ & $\begin{array}{c}61 \% \\
\text { esophagitis }\end{array}$ \\
\hline & & & $\begin{array}{l}68.4 \text { Gy total, } 41.4 \\
\text { Gy (1.8 Gy/d), then } \\
27 \text { Gy (1.5 Gy Bid) }\end{array}$ & $57 \% 3-y$ & $41 \% 3-y$ & $\begin{array}{c}10 \% \\
\text { esophagitis }\end{array}$ \\
\hline
\end{tabular}

Table 2. Results of Primary High-Dose Accelerated Fractionation/Hyperfractionation Combined Modality Therapy: Selected Series.

Wang et al. randomly assigned 101 patients with squamous cell cancer to receive either continuous accelerated hyperfractionated radiation (66 Gy) or late-course accelerated hyperfractionated radiation (68.4 Gy) (Wang et al., 2002). Compared with patients who received late-course accelerated hyperfractionated radiation, those treated with continuous accelerated hyperfractionated radiation had a significantly higher incidence of grade $3+$ esophagitis ( $61 \%$ vs. $10 \% ; P<.001)$; however, no benefit was seen in local control or survival. Although these approaches are reasonable, most series report an increase in acute toxicity without any clear therapeutic benefit. These regimens remain investigational.

\subsection{New combined modality regimens}

Because $75 \%$ to $80 \%$ of patients die of metastatic disease, advances in systemic therapies are necessary for further improvement of results. The most widely used chemotherapeutic regimen to be combined with radiation for the treatment of esophageal cancer is 5-FU and cisplatin. There are new chemotherapeutic agents both in current practice and in development for esophageal cancer. Most are being developed for use in preoperative regimens and are combined with radiation doses of 45 to $50.4 \mathrm{~Gy}$. Incorporation of these agents into chemotherapy regimens prior to chemoradiation or as adjuvant therapy may decrease systemic recurrence. Furthermore, new radiation sensitizers may improve locoregional control.

Multiple studies have tested both cytotoxic and targeted small molecules. Chemoradiation regimens using paclitaxel (Goldberg et al., 2003; Bains et al., 2002; Orditura et al., 2010; Ruppert et al., 2010), docetaxel (Pasini et al., 2005; Spigel et al., 2010), irinotecan (Ruppert 
et al., 2010; Ilson et al., 2002; Watkins et al., 2011; Sun et al., 2011), oxaliplatin (Spigel et al., 2010; De Vita et al., 2011; Chiarion-Sileni et al., 2009), epirubicin (Sun et al., 2011) and pemetrexed (Jatoi et al., 2010) have shown encouraging results. Biologic agents, such as cetuximab, trastuzumab, erlotinib, celecoxib and bevacizumab (De Vita et al., 2011; Safran et al., 2002; Enzinger et al., 2003; Suntharalingam et al., 2006) are being used as the foundations for new regimens which may enhance chemoradiation and target systemic micrometastases. Whether these investigational approaches offer improved results compared to conventional chemoradiation regimens based on 5-FU and cisplatin is not known.

\section{Conclusion}

For early esophageal cancer, endoscopic therapies are viable therapeutic options with significantly lower morbidities as compared to surgery. Currently, for a subset of patients with clinically localized early stage esophageal cancer (T0 or T1 lesions), local endoscopic therapy seems to be an acceptable alternative and produces similar results to surgery.

However, it is still unknown which of the endoscopic therapies represents the best alternative to surgical resection.

For more advanced stages of esophageal cancers, concurrent chemoradiation remains the standard nonsurgical treatment. New chemotherapeutic or biologic agents and radiation techniques are still needed to improve the survival of patients undergoing definitive chemoradiation.

\section{References}

Ackroyd R, Brown NJ, Davis MF, et al. Photodynamic therapy for dysplastic Barrett's oesophagus: a prospective, double blind, randomized, placebo controlled trial. Gut 2000; 47: 612-617.

Akagi Y, Hirokawa Y, Kagemoto M, et al. Optimum fractionation for high-dose-rate endoesophageal brachytherapy following external irradiation of early stage esophageal cancer. Int J Radiat Oncol Biol Phys 1999; 43:525-530.

Allington HV. Liquid nitrogen in the treatment of skin diseases. Calif Med 1950; 72: 153-155.

Al-Sarraf M, Martz K, Herskovic A, et al. Progress report of combined chemoradiotherapy versus radiotherapy alone in patients with esophageal cancer: an intergroup study. J Clin Oncol 1997; 15: 277-284. Erratum in: J Clin Oncol 1997; 15: 866.

Araujo CM, Souhami L, Gil RA, et al. A randomized trial comparing radiation therapy versus concomitant radiation therapy and chemotherapy in carcinoma of the thoracic esophagus. Cancer 1991;67:2258-2261.

Armstrong JG, High dose rate remote afterloading brachytherapy for lung and esophageal cancer. Semin Radiat Oncol 1993; 4:270-277.

Attwood SE, Lewis CJ, Caplin S, et al. Argon beam plasma coagulation as therapy for highgrade dysplasia in Barrett's esophagus. Clin Gastroenterol Hepatol 2003; 1: 258-263.

Badreddine RJ, Prasad GA, Wang KK, et al. Prevalence and predictors of recurrence neoplasia after ablation of Barrett's esophagus. Gastrointest Endosc 2010; 71: 697-703. 
Bains MS, Stojadinovic A, Minsky B, et al. A phase II trial of preoperative combinedmodality therapy for localized esophageal carcinoma: initial results. J Thorac Cardiovasc Surg 2002; 124:270-277.

Beaumont H, Bergman JJ, Pouw RE et 1 . Preservation of the functional integrity of the distal esophagus after circumferential ablation of Barrett's esophagus. Gastroenterol 2007; 132: A-A255.

Bedenne L, Michel P, and Binquet C et al. Chemoradiation followed by surgery compared with chemoradiation alone in squamous cancer of the esophagus: FFCD 9102. J Clin Oncol 2007; 25: 1160-1168.

Bonnetain F, Bouche $\mathrm{O}$, and Bedenne L et al. A comparative longitudinal quality of life study using the Spitzer quality of life index in a randomized multicenter phase III trial (FFCD 9102): chemoradiation followed by surgery compared with chemoradiation alone in locally advanced squamous resectable thoracic esophageal cancer. Ann Oncol 2006; 17: 827-834.

Buttar NS, Wang KK, Lutzke LS, et al. Combined endoscopic mucosal resection and photodynamic therapy for esophageal neoplasia within Barrett's esophagus. Gastrointest Endosc 2001; 54: 682-688.

Calais G, Jadaud E, Chapet S, et al. High dose radiotherapy (RT) and concomitant chemotherapy for nonresectable esophageal cancer. Results of a phase II study. Proc ASCO 1994; 13:197.

Calais G, Dorval E, Louisot P, et al. Radiotherapy with high dose rate brachytherapy boost and concomitant chemotherapy for stages IIB and III esophageal carcinoma: results of a pilot study. Int J Radiat Oncol Biol Phys 1997; 38: 769-775.

Caspers RJL, Zwinderman AH, Griffioen G, et al. Combined external beam and low dose rate intraluminal radiotherapy in oesophageal cancer. Radiother Oncol 1993; 27:712.

Chiarion-Sileni V, Innocente $\mathrm{R}$, Ancona $\mathrm{E}$ et al. Multicenter- phase II trial of chemoradiotherapy with 5-fluorouracil, leucovorin and oxaliplatin in locally advanced esophageal cancer. Cancer Chemother Pharmacol 2009; 63: 1111-1119.

Chiu PW, Chan AC, Ng EK et al. Multicenter prospective randomized trial comparing standard esophagectomy with chemoradiotherapy for treatment of squamous esophageal cancer: results from the Chinese University Research Group for Esophageal Cancer (CURE). J Gastrointest Surg 2005; 9: 794-802.

Coia LR, Engstrom PF, Paul AR, et al. Long-term results of infusional 5-FU, mitomycin-C, and radiation as primary management of esophageal cancer. Int J Radiat Oncol Biol Phys 1991; 20:29-36.

Coia LR, Minsky BD, Berkey BA, et al. Outcome of patients receiving radiation for cancer of the esophagus: results of the 1992-1994 patterns of care study. J Clin Oncol 2000; 18: 455-462.

Cooper JS, Guo MD, Herskovic A, et al. Chemoradiotherapy of locally advanced esophageal cancer. Long-term follow-up of a prospective randomized trial (RTOG 85-01). JAMA 1999; 281:1623-1627. 
De Vita F, Orditura M, Ciardiello F et al. A multicenter phase II study of induction chemotherapy with FOLFOX-4 and cetuximab followed by radiation and cetuximab in locally advanced oesophageal cancer. Br J Cancer 2011; 104: 427-432.

De-Ren S. Ten-year follow-up of esophageal cancer treated by radical radiation therapy: analysis of 869 patients. Int J Radiat Oncol Biol Phys 1989; 16: 329-334.

Downey RJ, Akhurst T, Ilson D, et al. Whole body 18FDG-PET and the response of esophageal cancer to induction therapy: results of a prospective trial. J Clin Oncol 2003; 21: 428-432.

Dulai GS, Jensen DM, Fontana L, et al. Randomized trial of argon plasma coagulation vs. multipolar electrocoagulation for ablation of Barrett's esophagus. Gastrontest Endosc 2005; 61: 232-240.

Dumot JA, Vargo JJ, Rice TW, et al. Preliminary results of cryotherapy ablation for esophageal high grade dysplasia (HGD) or intra-mucosal cancer (IMC) in high-risk non-surgical patients. Gastrointest Endosc 2007; 65: AB110.

Dunn J, Lovat L. Photodynamic therapy using 5-aminolaevulinic acid for the treatment of dysplasia in Barrett's oesophagus. Expert Opin Pharmacother 2008; 9: 851-858.

Ell C, May A, Pech O, et al. Curative endoscopic resection of early esophageal adenocarcinoma (Barrett's cancer). Gastrointest Endosc 2007; 65: 3-10.

Enzinger PC, Mamon H, Bueno R, et al. Phase II cisplatin, irinotecan, celecoxib and concurrent radiation therapy followed by surgery for locally advanced esophageal cancer. Proc ASCO 2003; 22:361.

Finkelstein SD, Lyday WD. The molecular pathology of radiofrequency mucosal ablation of Barrett's esophagus. Gastroenterol 2008; 134: A436.

Flamen P, Van Cutsem E, Lerut A, et al. Positron emission tomography for assessment of the response to induction radiochemotherapy in locally advanced oesophageal cancer. Ann Oncol 2002; 13:361-368.

Fleischer DE, Overholt BF, Sharma VK et al. Endoscopic ablation of Barrett's esophagus: a multicenter study with 2.5-year follow-up. Gastrointest Endosc 2008; 68: 867-876.

Gaspar LE, Nag S, Herskovic A, et al. American Brachytherapy Society (ABS) consensus guidelines for brachytherapy of esophageal cancer. Int J Radiat Oncol Biol Phys 1997; 38:127-132.

Gaspar LE, Qian C, Kocha WI, et al. A phase I/II study of external beam radiation, brachytherapy and concurrent chemotherapy in localized cancer of the esophagus (RTOG 92-07): preliminary toxicity report. Int J Radiat Oncol Biol Phys 1997; 37:593599.

Giovannini M, Bories E, Pesenti C, et al. Circumferential endoscopic mucosal resection in Barrett's esophagus with high grade intraepithelial neoplasia or mucosal cancer: preliminary results in 21 patients. Endoscopy 2004; 36: 782-787.

Girinsky T, Auperin A, Marsiglia H, et al. Accelerated fractionation in esophageal cancers: a multivariate analysis on 88 patients. Int J Radiat Oncol Biol Phys 1997; 38:10131018.

Goldberg M, Farma J, Weiner LM et al. Survival following intensive preoperative combined modality therapy with paclitaxel, cisplatin, 5-fluorouracil, and radiation in 
resectable esophageal carcinoma: A phase I report. J Thorac Cardiovasc Surg 2003; 126: 1168-1173.

Gomi K, Oguchi M, Hirokawa Y, et al. Process and preliminary outcome of a patterns of care study of esophageal cancer in Japan: patients treated with surgery and radiotherapy. Int J Radiat Oncol Biol Phys 2003; 56: 813-822.

Gondrie JJ, Rygiel AM, Sondermeijer CM et al. Balloon-based circumferential ablation followed by focal ablation of Barrett's esophagus containing high-grade dysplasia effectively removes all genetic alterations. Gastroenterol 2007; 132: A-A64.

Gondrie JJ, Pouw RE,Sondermeijer CM et al. Effective treatment of early Barrett's neoplasia with stepwise circumferential and focal ablation using the HALO system. Endoscopy 2008; 40: 370-379.

Gondrie JJ, Pouw RE, Sondermeijer CM et al. Stepwise circumferential and focal ablation of Barrett's esophagus with high-grade dysplasia: results of the first prospective series of 11 patients. Endoscopy 2008; 40: 359-369.

Gossner L, May A, Stolte M, et al. KTP laser destruction of dysplasia and early cancer in columnar-lined Barrett's esophagus. Gastrointest Endosc 1999; 49: 8-12.

Greenwald BD, Horwhat JD, Abrams JA, et al. Endoscopic cryotherapy ablation is safe and well-tolerated in Barrett's esophagus, esophageal dysplasia, and esophageal cancer. Gastrointest Endosc 2008; 67: AB76.

Greenwald BD, Dumot JA, Wolfsen HC, et al. Endoscopic spray cryotherapy for esophageal cancer: safety and efficacy. Gastrointest Endosc 2010; 71: 686-693.

Gross SA, Wolfsen HC. The role of photodynamic therapy in the esophagus. Gastrointestinal Endosc Clin N Am. 2010; 20: 35-53.

Hage M, Siersma PD, van Dekken $\mathrm{H}$ et al. 5-aminolevulinic acid photodynamic therapy versus argon plasma coagulation for ablation of Barrett's oesophagus: a randomized trial. Gut 2004; 53: 785-790.

Herskovic A, Martz K, Al-Sarraf M, et al. Combined chemotherapy and radiotherapy compared with radiotherapy alone in patients with cancer of the esophagus. $\mathrm{N}$ Engl J Med 1992; 326:1593-1598.

Hironaka S, Hasebe T, Kamijo T, et al. Biopsy specimen microvessel density is a useful prognostic marker in patients with $\mathrm{T} 2-4 \mathrm{M} 0$ esophageal cancer treated with chemoradiotherapy. Clin Cancer Res 2002; 8:124-130.

Holmes SR and Vaughan LT. Epidemiology and pathogenesis of esophageal cancer. Seminars in Radiation Oncology 2007; 17: 2-9.

Ilson DH, Minsky B, Kelsen D. Irinotecan, cisplatin and radiation in esophageal cancer. Oncology 2002; 16s:11-15.

Ilson DH, Bains M, Kelsen DP, et al. Phase I trial of escalating-dose irinotecan given weekly with cisplatin and concurrent radiotherapy in locally advanced esophageal cancer. J Clin Oncol 2003; 21:2926-2932.

Ishikura S, Nihei K, Ohtsu A, et al. Long-term toxicity after definitive chemoradiotherapy for squamous cell carcinoma of the thoracic esophagus. J Clin Oncol 2003; 21:26972702. 
Izquierdo MA, Marcuello E, Gomez de Segura G, et al. Unresectable nonmetastatic squamous cell carcinoma of the esophagus managed by sequential chemotherapy (cisplatin and bleomycin) and radiation therapy. Cancer 1993; 71:287-292.

Jager J, Langendijk H, Pannebakker M, et al. A single session of intraluminal brachytherapy in palliation of esophageal cancer. Radiother Oncol 1995; 37:237-240.

Jatoi A, Soori G, Alberts SR et al. Phase II study of preoperative pemetrexed, carboplatin, and radiation followed by surgery for locally advanced esophageal cancer and gastroesophageal junction tumors. J Thorac Oncol 2010; 5: 1994-1998.

Jeremic B, Shibamoto Y, Acimovic L, et al. Accelerated hyperfractionated radiation therapy and concurrent 5-fluorouracil/cisplatin chemotherapy for locoregional squamous cell carcinoma of the thoracic esophagus: a phase II study. Int J Radiat Oncol Biol Phys 1998; 40:1061-1066.

Johnston M, Eastone JA, Horwhat JD, et al. Cryoablation of Barrett's esophagus: a pilot study. Gastrointest Endosc 2005; 62: 842-848.

Kelsen DP, Minsky B, Smith M, et al. Preoperative therapy for esophageal cancer: a randomized comparison of chemotherapy versus radiation therapy. J Clin Oncol 1990:1352-1361.

Kishi K, Doki Y, Miyata H, et al. Prediction of the response to chemoradiation and prognosis in oesophageal squamous cancer. Br J Surg 2002; 89:597-603.

Kok TC, Lanschot JV, Siersema PD, et al. Neoadjuvant chemotherapy in operable esophageal squamous cell cancer: final report of a phase III multicenter randomized trial. Proc ASCO 1997;16:277.

Larghi A, Lightdale CJ, Ross AS, et al. Long-term follow-up of complete Barrett's eradication endoscopic mucosal resection (CBE-EMR) for the treatment of high grade dysplasia and intramucosal carcinoma. Endoscopy 2007; 39: 1086-1091.

Lightdale CJ, Heier SK, Marcon NE, et al. Photodynamic therapy with porfimer sodium versus thermal ablation therapy with $\mathrm{Nd}$ : YAG laser for palliation of esophageal cancer: a multicenter randomized trial. Gastrointest Endosc 1995; 42:507-512.

Lopes CV, Hela M, Pesenti C, et al. Circumferential endoscopic resection of Barrett's esophagus with high grade dysplasia or early adenocarcinoma. Surg Endosc 2007; 21: 820-824.

Maingon P, d'Hombres A, Truc G, et al. High dose rate brachytherapy for superficial cancer of the esophagus. Int J Radiat Oncol Biol Phys 2000; 46:71-76.

Maunoury V. Mordon S., Mariette C., et al. Photodynamic therapy for early oesophageal cancer. Digestive and Liver Disease. 2005; 37: 491-495.

Merchant TE, Minsky BD, Lauwers GY, et al. Esophageal cancer phospholipids correlated with histopathologic findings: a 31P NMR study. NMR Biomed 1999; 12:184-188.

Michopoulos S, Tsibouris P, Bouzakis H et al. Complete regression of Barrett's esophagus with heat probe thermocoagulation: mid-term results. Gastrointest Endosc 1999; 50: 165-172.

Minsky BD, Neuberg D, Kelsen DP, et al. Final report of intergroup trial 0122 (ECOG PE289, RTOG 90-12): phase II trial of neoadjuvant chemotherapy plus concurrent chemotherapy and high-dose radiation for squamous cell carcinoma of the esophagus. Int J Radiat Oncol Biol Phys 1999; 43:517-523. 
Minsky BD, Pajak T, Ginsberg RJ, et al. INT 0123 (RTOG 94-05) phase III trial of combined modality therapy for esophageal cancer: high dose (64.8 Gy) vs. standard dose (50.4 Gy) radiation therapy. J Clin Oncol 2002; 20:1167-1174.

Miros M, Kerlin P, Walker N. Only patients with dysplasia progress to adenocarcinoma in Barrett's esophagus. Gut 1991; 32: 1441-1446.

Moghissi K, Dixon Hons KBA, Thorpe JAC, et al. Photofrin PDT for early stage oesophageal cancer: long term results in 40 patients and literature review. Photodiag and Photodyn 2009; 6: 159-166.

Moni J, Armstrong JG, Minsky BD, et al. High dose rate intraluminal brachytherapy for carcinoma of the esophagus. Dis Esophagus 1996; 9:123-127.

Morita M, Kuwano H, Araki K, et al. Prognostic significance of lymphocytic infiltration following preoperative chemoradiotherapy and hyperthermia for esophageal cancer. Int J Radiat Oncol Biol Phys 2001; 49:1259-1266.

Nemoto K, Yamada S, Hareyama M, et al. Radiation therapy for superficial esophageal cancer: a comparison of radiotherapy methods. Int J Radiat Oncol Biol Phys 2001; 50:639-644.

Nemoto K, Zhao HJ, Goto T, et al. Radiation therapy for limited-stage small-cell esophageal cancer. Am J Clin Oncol 2002; 25: 404-407.

Newaishy GA, Read GA, Duncan W, et al. Results of radical radiotherapy of squamous cell carcinoma of the esophagus. Clin Radiol 1982; 33: 347-352.

Nishioka NS. Drug, light and oxygen: a dynamic combination in the clinic. Gastroenterol 1998; 114: 604-606.

Nutting CM, Bedford JL, Cosgrove VP, et al. A comparison of conformal and intensitymodulated techniques for oesophageal radiotherapy. Radiother Oncol 2001; 61:157163.

Nygaard K, Hagen S, Hansen HS, et al. Pre-operative radiotherapy prolongs survival in operable esophageal carcinoma: a randomized, multicenter study of pre-operative radiotherapy and chemotherapy. The second Scandinavian trial in esophageal cancer. World J Surg 1992; 16:1104-1109.

Okawa T, Kita M, Tanaka M, et al. Results of radiotherapy for inoperable locally advanced esophageal cancer. Int J Radiat Oncol Biol Phys 1989; 17:49-54.

Okawa T, Dokiya T, Nishio M, et al. Multi-institutional randomized trial of external radiotherapy with and without intraluminal brachytherapy for esophageal cancer in Japan. Int J Radiat Oncol Biol Phys 1999; 45:623-628.

Orditura M, Galizia G, Devita F et al. Weekly chemotherapy with cisplatin and paclitaxel and concurrent radiation therapy as preoperative treatment in locally advanced esophageal cancer: a phase II study. Cancer Invest 2010; 28: 820-827.

Ott K, Fink U, Becker K, et al. Prediction of response to preoperative chemotherapy in gastric carcinoma by metabolic imaging: results of a prospective trial. J Clin Oncol 2003; 21:4604-4610.

Overholt BF, Panjehpour M, Haydek JM. Photodynamic therapy for Barrett's esophagus: follow-up in 100 patients. Gastrointest Endosc 1999; 49: 1-7. 
Overholt BF, Panjehpour M, Halberg DL. Photodynamic therapy for Barrett's esophagus with dysplasia and/or early stage carcinoma: long term results. Gastrointest Endosc 2003; 58: 183-188.

Overholt BF, Lightdale CJ, Wang KK, et al. Photodynamic therapy with porfimer sodium for ablation of high-grade dysplasia in Barrett's esophagus: international, partially blinded, randomized phase III trial. Gastrointestinal Endosc 2005; 62: 488-98.

Overholt BF, Wang KK, Burdick S, et al. Five-year efficacy and safety of photodynamic therapy with Photofrin in Barrett's high-grade dysplasia. Gastrointest Endosc 2007; 66: 460-468.

Pasini F, de Manzoni G, Cordiano C, et al. High pathologic response rate in locally advanced esophageal cancer after neoadjuvant combined modality therapy: dose finding of a weekly chemotherapy schedule with protracted venous infusion of 5-fluorouracil and dose escalation of cisplatin, docetaxel and concurrent radiotherapy. Ann Oncol 2005; 16: 1133-1139.

Pech O, Gossner L, May A, et al. Long-term results of photodynamic therapy with 5aminolevulinic acid for superficial Barrett's cancer and high-grade intraepithelial neoplasia. Gastrointest Endosc 2005; 62: 24-30.

Pereira-Lima JC, Busnello JV, Saul C, et al. High power setting argon plasma coagulation for the eradication of Barrett's esophagus. Am J Gastroenterol 2000; 95: 1661-1668.

Peters F, Kara M, Rosmolen W, et al. Poor results of 5-aminolevulinic acid-photodynamic therapy for residual high-grade dysplasia and early cancer in Barrett esophagus after endoscopic resection. Endoscopy 2005; 37: 418-424.

Peters FP, Kara MA, Rosmolen WD, et al. Stepwise radical endoscopic resection is effective for complete removal of Barrett's esophagus with early neoplasia: a prospective study. Am J Gastroenterol 2006; 101: 1449-1457.

Peters FP, Brakenhoff KP, Curvers WL et al. Histologic evaluation of resection specimens obtained at 293 endoscopic resections in Barrett's esophagus. Gastrointest Endosc 2008; 67: 604-609.

Phillips TL, Minsky BD, Dicker A. Cancer of the esophagus. In: Leibel S, Phillips TL, eds. Textbook of radiation oncology. Philadelphia: WB Saunders, 1998: 601-612.

Pomp J, Davelaar J, Blom J, et al. Radiotherapy for oesophagus carcinoma: the impact of p53 on treatment outcome. Radiother Oncol 1998; 46:179-184.

Poplin EA, Jacobson J, Herskovic A, et al. Evaluation of multimodality treatment of locoregional esophageal carcinoma by Southwest Oncology Group 9060. Cancer 1996; 78:1851-1856.

Prasad GA, Wang KK, Buttar NS, et al. Long-term survival following endoscopic and surgical treatment of high-grade dysplasia in Barrett's esophagus. Gastroenterol 2007; 132: 1226-1233.

Prasad GA, Wang KK, Buttar NS, et al. Predictors of stricture formation after photodynamic therapy for high-grade dysplasia in Barrett's esophagus. Gastrointest Endosc 2007; 65: 60-66.

Prasad GA, Wang KK, Halling KC, et al. Utility of biomarkers in prediction of response to ablative therapy in Barrett's esophagus. Gastroenterol 2008; 135: 370-379. 
Prasad GA, Wu TT, Wigle DA, et al. Endoscopic and surgical treatment of mucosal (T1a) esophageal adenocarcinoma in Barrett's esophagus. Gastroenterol 2009; 137: 815823.

Ragunath K, Krasner N, Raman VS, et al. Endoscopic ablation of dysplastic Barrett's oesophagus comparing argon plasma coagulation and photodynamic therapy: a randomized prospective trial assessing efficacy and cost-effectiveness. Scand J Gastroenterol 2005; 40: 750-758.

Reid BJ, Levine DS, Longton G, et al. Predictors of progression to cancer in Barrett's esophagus : baseline histology and flow cytometry identify low-and high-risk patient subsets. Am J Gastroenterology 2000; 95: 1669-1676.

Roca E, Pennella E, Sardi M, et al. Combined intensive chemoradiotherapy for organ preservation in patients with resectable and non-resectable oesophageal cancer. Eur J Cancer 1996; 32A:429-432.

Roussel A, Jacob JH, Jung GM, et al. Controlled clinical trial for the treatment of patients with inoperable esophageal carcinoma: a study of the EORTC Gastrointestinal Tract Cancer Cooperative Group, in recent results in cancer research. In: Schlag P, Hohenberger P, Metzger U, eds. Berlin: Springer-Verlag, 1988:21-28.

Ruppert BN, Watkins JM, Sharma AK et al. Cisplatin/irinotecan versus carboplatin/paclitaxel as definitive chemoradiotherapy for locoregionally advanced esophageal cancer. Am J Clin Oncol 2010; 33:346-352.

Safran H, DiPetrillo T, Nadeem A, et al. Neoadjuvant Herceptin, paclitaxel, cisplatin, and radiation for adenocarcinoma of esophagus: a phase I study. Proc ASCO 2002; 21:141a.

Sampliner RE, Faigel D, Fennerty B, et al. Effective and safe endoscopic reversal of nondysplastic Barrett's esophagus with thermal electrocoagulation combined with high-dose acid inhibition: a multicenter study. Gastrointest Endosc 2001; 53: 554558.

Sarbia M, Stahl M, Fink U, et al. Expression of apoptosis-regulating proteins and outcome of esophageal cancer patients treated by combined therapy modalities. Clin Cancer Res 1998; 4:2991-2997.

Schraube P, Fritz P, Wannenmacher MF. Combined endoluminal and external irradiation of inoperable oesophageal carcinoma. Radiother Oncol 1997; 44:45-51.

Schulz H, Miehlke S, Antos D et al. Ablation of Barrett's epithelium by endoscopic argon plasma coagulation in combination with high-dose omeprazole. Gastrointest Endosc 2000; 51: 659-663.

Seewald S, Akaraviputh T, Seitz U, et al. Circumferential EMR and complete removal of Barrett's epithelium: a new approach to management of Barrett's esophagus containing high grade intraepithelial neoplasia and intramucosal carcinoma. Gastrointest Endosc 2003; 57: 854-859.

Seitz JF, Giovannini M, Padaut-Cesana J, et al. Inoperable nonmetastatic squamous cell carcinoma of the esophagus managed by concomitant chemotherapy (5fluorouracil and cisplatin) and radiation therapy. Cancer 1990; 66:214-219.

Seki K, Karasawa K, Kohno M, et al. The treatment result of definitive radiotherapy for superficial esophageal cancer. Int J Radiat Oncol Biol Phys 2001; 51:264-268. 
Shaheen NJ, Sharma P, Overholt BF e tal. A randomized, multicenter, sham-controlled trial of radiofrequency ablation (RFA) for subjects with Barrett's esophagus containing dysplasia: interim results of the AIM dysplasia trial. Gastroenterol 2008; 134: AA37.

Shaheen NJ, Sharma P, Lightdale CJ et al. Radiofrequency ablation in Barrett's esophagus with dysplasia. N Eng J Med 2009; 360: 2277-2288.

Sharma P. Jaffe PE, Sampliner RE, et al. Laser and multipolar electrocoagulation ablation of early Barrett's adenocarcinoma: long-term follow. Gastrointest Endosc 1999; 49: 442-446.

Sharma P, McQuaid, DentJ, et al. A critical review of the diagnosis and management of Barrett's esophagus: the AGA Chicago workshop. Gastroenterology 2004; 127:310330.

Sharma VK, Kim HJ, Das A et al. Successful ablation of Barrett's esophagus with dysplasia using the HALO360 ablation system: a single-center experience (abstract). Am J Gastrointest 2006; 101: 535.

Sharma VK, Wang KK, Overholt BF et al. Balloon-based, circumferential, endoscopic radiofrequency ablation of Barrett's esophagus: 1-year follow-up of 100 patients. Gastrointest Endosc 2007; 65: 185-195.

Shi X, Yao W, Liu T. Late course accelerated fractionation in radiotherapy of esophageal carcinoma. Radiother Oncol 1999; 51:21-26.

Slabber CF, Nel JS, Schoeman L, et al. A randomized study of radiotherapy alone versus radiotherapy plus 5-fluorouracil and platinum in patients with inoperable, locally advanced squamous cell cancer of the esophagus. Am J Clin Oncol 1998:21:462-465.

Smith TJ, Ryan LM, Douglass HO, et al. Combined chemoradiotherapy vs. radiotherapy alone for early stage squamous cell carcinoma of the esophagus: a study of the Eastern Cooperative Oncology Group. Int J Radiat Oncol Biol Phys 1998; 42:269276.

Spechler SJ. Dysplasia in Barrett's esophagus: limitations of current management strategies. Am J Gastroenterology 2005; 100: 927-935.

Spigel DR, Greco FA, Hainsworth JD et al. Phase I/II trial of preoperative oxaliplatin, docetaxel, capecitabine with concurrent radiation therapy in localized carcinoma of the esophagus or gastroesophageal junction. J Clin Oncol 2010; 28: 2213-2219.

Stahl M, Stuschke M, and Wilke $\mathrm{H}$ et al.Chemoradiation with and without surgery in patients with locally advanced squamous cell carcinoma of esophagus. J Clin Oncol 2005; 23: 2310-2317.

Streeter OE, Martz KL, Gaspar LE, et al. Does race influence survival for esophageal cancer patients treated on the radiation and chemotherapy arm of RTOG \# 85-01? Int J Radiat Oncol Biol Phys 1999;44:1047-1052.

Sun W, Metz JM, Haller DG et al. Two phase I studies of concurrent radiation therapy with continuous-infusion-5fluorouracil plus epirubicin, and either cisplatin or irinotecan for locally advanced upper gastrointestinal adenocarcinomas. Cancer Chemother Pharmacol 2011; 67: 621-627. 
Suntharalingam M, Moughhan J, Coia LR, et al. The national practice for patients receiving radiation therapy for carcinoma of the esophagus: results of the 1996-1999 Patterns of Care Study. Int J Radiat Oncol Biol Phys 2003; 56: 981-987.

Suntharalingam M, Dipetrillo T, Safran H et al. Cetuximab, carboplatin and paclitaxel and radiation for esophageal and gastric cancer. Proc J Clin Oncol 2006: 4029.

Sur RK, Singh DP, Sharma SC. Radiation therapy of esophageal cancer: role of high dose rate brachytherapy. Int J Radiat Oncol Biol Phys 1992; 22:1043-1046.

Sur RK, Donde B, Levin VC, et al. Fractionated high dose rate intraluminal brachytherapy in palliation of advanced esophageal cancer. Int J Radiat Oncol Biol Phys 1998; 40:447453.

Sykes AJ, Burt PA, Slevin NJ, et al. Radical radiotherapy for carcinoma of the oesophagus: an effective alternative to surgery. Radiother Oncol 1998; 48:15-21.

Tai P, van Dyk J, Battista J, et al. Improving the consistency in cervical esophageal target volume definition by special training. Int J Radiat Oncol Biol Phys 2002; 53:766774.

Thomas T, Abrams KR, de Caestecker JS, Robinson RJ. Meta analysis: cancer risk in Barrett's esophagus. Aliment Pharmacol Ther 2007; 26:1465-1477.

Valerdi JJ, Tejedor M, Illarramendi JJ, et al. Neoadjuvant chemotherapy and radiotherapy in locally advanced esophagus carcinoma: long term results. Int J Radiat Oncol Biol Phys 1994; 27:843-847.

Van Laethem JL, Jagodzinski R, Peny MO et al. Argon plasma coagulation in the treatment of Barrett's high-grade dysplasia and in-situ adenocarcinoma. Endosc 2001; 33: 257261.

Wang Y, Shi XH, He SQ, et al. Comparison between continuous accelerated hyperfractionated and late-course accelerated hyperfractionated radiotherapy for esophageal carcinoma. Int J Radiat Oncol Biol Phys 2002; 54:131-136.

Watkins JM, Zauls AJ, Sharma AK et al. Toxicity, response rates and survival outcomes of induction cisplatin and irinotecan followed by concurrent cisplatin, irinotecan and radiotherapy for locally advanced esophageal cancer. Jpn J Clin Oncol 2011; 41: 334-342.

Westerterp M, Koppert LB, Buskens CJ e tal. Outocme of surgical treatment for early adenocarcinoma of the esophagus or gastro-esophageal junction. Virchows Arch 2005; 446: 497-504.

Wolfsen HC, Woodward TA, Raimondo M. Photodynamic therapy for dysplastic Barrett's esophagus and early esophageal adenocarcinoma. Mayo Clin Proc 2002; 77: 11761181.

Wolfsen HC, Hemminger LL, Wallace MB, et al. Clinical experience of patients undergoing photodynamic therapy for Barrett's dysplasia or cancer. Aliment Pharmacol Ther 2004; 20: 1125-1131.

Wong R, Malthaner R. Combined chemotherapy and radiotherapy (without surgery) compared with radiotherapy alone in localized carcinoma of the esophagus. Cochrane Database Syst Rev. 2006. Review. Update in: Cochrane Database Syst Rev. 2010. 
Yachimski P, Puricelli WP, Nishioka NS. Patient predictors of esophageal stricture development after photodynamic therapy. Clin Gastroenterol Hepatol 2008; 6: 302308.

Yachimski P, Puricelli WP, Nishioka NS. Patient predictors of histopathologic response after photodynamic therapy of Barrett's esophagus with high-grade dysplasia or intramucosal carcinoma. Gastrointest Endosc 2009; 69: 205-212.

Yorozu A, Dokiya T, Oki Y, et al. Curative radiotherapy with high-dose-rate brachytherapy boost for localized esophageal carcinoma: dose-effect relationship of brachytherapy with the balloon type applicator system. Radiother Oncol 1999; 51:133-139. 


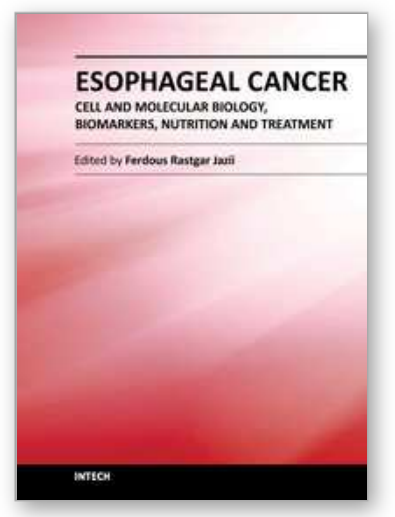

\author{
Esophageal Cancer - Cell and Molecular Biology, Biomarkers, \\ Nutrition and Treatment \\ Edited by Prof. Ferdous Rastgar Jazii
}

ISBN 978-953-51-0223-6

Hard cover, 244 pages

Publisher InTech

Published online 07, March, 2012

Published in print edition March, 2012

Esophageal Cancer illustrates recent achievements and investigations in the esophageal tumorigenesis from different perspectives. Readers find mechanisms involved in esophageal tumorigenesis, cellular, molecular, genetic, epigenetics, and proteomics, their relevance as the novel biomarkers and application in esophageal cancer diagnosis and therapy. The book covers detailed effect of nutritional factors in addition to ethanol metabolic pathway in the inhibition of retinoic acid metabolism and supply. Diagnosis, classification, and treatment of esophageal cancer, application of both surgical and non surgical methods as well as follow up of the disease are described in detail. Moreover readers are endowed with especial features of esophageal cancer such as multiple early stage malignant melanoma and pulmonary edema induced by esophagectomy, the two features that received less attention elsewhere in literature.

\title{
How to reference
}

In order to correctly reference this scholarly work, feel free to copy and paste the following:

Malek M. Safa and Hassan K. Reda (2012). Nonsurgical Management of Esophageal Cancer, Esophageal Cancer - Cell and Molecular Biology, Biomarkers, Nutrition and Treatment, Prof. Ferdous Rastgar Jazii (Ed.), ISBN: 978-953-51-0223-6, InTech, Available from: http://www.intechopen.com/books/esophageal-cancer-celland-molecular-biology-biomarkers-nutrition-and-treatment/nonsurgical-management-of-esophageal-cancer

\section{INTECH}

open science | open minds

\author{
InTech Europe \\ University Campus STeP Ri \\ Slavka Krautzeka 83/A \\ 51000 Rijeka, Croatia \\ Phone: +385 (51) 770447 \\ Fax: +385 (51) 686166 \\ www.intechopen.com
}

\author{
InTech China \\ Unit 405, Office Block, Hotel Equatorial Shanghai \\ No.65, Yan An Road (West), Shanghai, 200040, China \\ 中国上海市延安西路65号上海国际贵都大饭店办公楼 405 单元 \\ Phone: +86-21-62489820 \\ Fax: +86-21-62489821
}


(C) 2012 The Author(s). Licensee IntechOpen. This is an open access article distributed under the terms of the Creative Commons Attribution 3.0 License, which permits unrestricted use, distribution, and reproduction in any medium, provided the original work is properly cited. 